\title{
Complementation of Mutant and Wild-Type Human Mitochondrial DNAs Coexisting since the Mutation Event and Lack of Complementation of DNAs Introduced Separately into a Cell within Distinct Organelles
}

\author{
MAKOTO YONEDA, ${ }^{1}$ TADASHI MIYATAKE, ${ }^{2}$ AND GIUSEPPE ATTARDI ${ }^{1}$ * \\ Division of Biology, California Institute of Technology, Pasadena, California 91125, ${ }^{1}$ and \\ Department of Neurology, Tokyo Medical and Dental University, \\ Tokyo 113, Japan ${ }^{2}$
}

Received 29 November 1993/Accepted 12 January 1994

\begin{abstract}
The rules that govern complementation of mutant and wild-type mitochondrial genomes in human cells were investigated under different experimental conditions. Among mitochondrial transformants derived from an individual affected by the MERRF (myoclonus epilepsy associated with ragged red fibers) encephalomyopathy and carrying in heteroplasmic form the mitochondrial tRNA ${ }^{\text {Lys }}$ mutation associated with that syndrome, normal protein synthesis and respiration was observed when the wild-type mitochondrial DNA exceeded $10 \%$ of the total complement. In these transformants, the protective effect of wild-type mitochondrial DNA was shown to involve interactions of the mutant and wild-type gene products. Very different results were obtained in experiments in which two mitochondrial DNAs carrying nonallelic disease-causing mutations were sequentially introduced within distinct organelles into the same human mitochondrial DNA-less $\left(\rho^{0}\right)$ cell. In transformants exhibiting different ratios of the two genomes, no evidence of cooperation between their products was observed, even 3 months after the introduction of the second mutation. These results pointed to the phenotypic independence of the two genomes. A similar conclusion was reached in experiments in which mitochondria carrying a chloramphenicol resistance-inducing mitochondrial DNA mutation were introduced into chloramphenicol-sensitive cells. A plausible interpretation of the different results obtained in the latter two sets of experiments, compared with the complementation behavior observed in the heteroplasmic MERRF transformants, is that in the latter, the mutant and wild-type genomes coexisted in the same organelles from the time of the mutation. This would imply that the way in which mitochondrial DNA is sorted among different organelles plays a fundamental role in determining the oxidative-phosphorylation phenotype in mammalian cells. These results have significant implications for mitochondrial genetics and for studies on the transmission and therapy of mitochondrial DNA-linked diseases.
\end{abstract}

Despite the large number of studies on the expression of artificially produced mitochondrial DNA (mtDNA) mutations and the phenotype of somatic cell hybrids and cybrids, information on mitochondrial genome interactions in mammalian cells is still very limited. The dependence of such interactions on the distribution of the mtDNA molecules among the mitochondria, which changes continuously throughout division and, possibly, fusion of the organelles, and the difficulty of investigating mtDNA sorting in a cell account in part for the present lack of understanding of how much the mitochondrial genomes interact in mammalian cells. The recent discovery of a variety of mtDNA mutations associated with diseases in humans (47) and the growing evidence of accumulation of mtDNA mutations with aging in somatic tissues $(12-14,19,43)$ have raised a number of questions about the occurrence and frequency of intermixing of mutant and wild-type mtDNA and/or their products within a cell and the role that complementation or competition phenomena between these products play in determining the cell phenotype. While it is clear that the respiratory competence of a cell containing both mutant and wild-type mtDNA (heteroplasmic) depends on the proportion of the two types of mtDNA and on the capacity of their products to cooperate or compete with each other, only

\footnotetext{
* Corresponding author.
}

fragmentary data on the mechanisms which would permit such cooperation or competition to occur are available.

Evidence derived from the analysis of heteroplasmic cybrids produced by transfer of mitochondria from patients affected by the MELAS (mitochondrial myopathy, encephalopathy, lactic acidosis, and stroke-like episodes) encephalomyopathy, caused by a mitochondrial tRNA ${ }^{\text {Leu(UUR) }}$ mutation, into mtDNA-less $\left(\rho^{0}\right)$ cells $(8)$ and from the investigation of myotubes that are heteroplasmic for the MERRF (myoclonus epilepsy associated with ragged red fibers) mitochondrial tRNA ${ }^{\text {Lys }}$ mutation (5) has clearly indicated that a small minority of wild-type mtDNA can protect the cell against the phenotypic effects of the mtDNA mutation. However, such experiments did not clarify whether this protective effect reflects the capacity of the wild-type mtDNA minority to provide enough respiratory capacity for the cellular needs even when completely segregated from the mutant mtDNA or, alternatively, whether intermixing and cooperation of the wild-type and mutant gene products, presumably through mitochondrial fusion, are required for the protective effect to occur.

Evidence suggesting cooperation between the products of wild-type and deleted mtDNA in cybrids derived from cells of a patient affected by chronic external ophthalmoplegia has been provided by the observation of translation products corresponding in size to the expected fusion proteins encoded in the deleted mtDNA (20). In fact, because of the removal of 
essential tRNA genes by the deletion, the synthesis of such fusion products would require the participation of tRNAs transcribed from the wild-type genomes. Similarly, competition for tRNAs encoded in wild-type mtDNA by mRNAs transcribed from wild-type and mutant mtDNAs, again pointing to intermixing of mitochondrial gene products, has been suggested to occur in segments of skeletal muscle fibers of patients affected by a mitochondrial disease (Kearns-Sayre syndrome) characterized by accumulation of large-scale deletions in mtDNA (41). However, in both of the above-mentioned cases, the results could not distinguish between the possibility that the presence of normal and deleted mtDNAs in the same mitochondrion resulted from fusion of two homoplasmic mitochondria, one containing only deleted mtDNA and the other containing only wild-type mtDNA, and the preexistence of both mtDNAs in the same mitochondrion from the time of the mutation event. Evidence which had been interpreted to suggest an intermixing and cooperation of gene products of mutant and wild-type mtDNAs originally carried in distinct organelles had been reported in an earlier study involving hybrids or cybrids between chloramphenicol (CAP)-sensitive $\left(\mathrm{CAP}^{\mathrm{s}}\right)$ human cells and CAP-resistant $\left(\mathrm{CAP}^{\mathrm{r}}\right)$ cells or cytoplasts derived therefrom, respectively (35).

In this study, the availability of donor cells derived from patients affected by either of two mitochondrial diseases caused by mutations in distinct mitochondrial tRNA genes has allowed us to introduce independently the two mtDNAs into the same $\rho^{0}$ cell and thus to test the occurrence of complementation between mitochondrial genomes carried by originally distinct organelles in the absence of a significant background due to lack of complementation. No evidence of cooperation was observed between the products of the two genomes, pointing to the phenotypic independence of these genomes. Similarly, no interactions between mutant and wildtype mtDNAs were detected in experiments in which mitochondria carrying CAPr mtDNA were introduced by cytoplast fusion into CAPs cells. In contrast to the above situations, in heteroplasmic MERRF transformants, derived from donor cells in which the mutant and wild-type genomes coexisted from the mutation event, extensive interactions between mutant and wild-type gene products were observed, pointing to a probable intramitochondrial event.

\section{MATERIALS AND METHODS}

Cell lines and media. The bromodeoxyuridine (BrdU)resistant 143B.TK ${ }^{-}$cell line (ATCC CRL 8303; hereafter referred to as 143B) was grown in Dulbecco's modified Eagle's medium (DMEM) containing $4.5 \mathrm{mg}$ of glucose per $\mathrm{ml}$ and supplemented with $5 \%$ fetal calf serum (FBS) and $100 \mu \mathrm{g}$ of BrdU per ml. The $\rho^{0} 206$ cell line, an mtDNA-less derivative of 143B. TK ${ }^{-}$obtained by long-term exposure of the cells to low concentrations of ethidium bromide (25), was grown in DMEM supplemented with 5\% FBS plus $100 \mu \mathrm{g}$ of BrdU and $50 \mu \mathrm{g}$ of uridine per ml. Transformant pT72, derived from a myoblast culture from an MERRF patient by mitochondrion transfer into the $\rho^{0} 701.2 \mathrm{a}$ cell line (obtained by ethidium bromide treatment of the simian virus 40 -transformed human fibroblast strain GM701 [26a]) (9), was grown in DMEM supplemented with $10 \%$ FBS. The other transformants used in the present work were grown in DMEM supplemented with $5 \%$ (MERRF transformants) or 10\% (MELAS and doublegenome transformants) dialyzed FBS and $100 \mu \mathrm{g}$ of BrdU per $\mathrm{ml}$ except for transformants $59 \mathrm{~A} \times \mathrm{pT} 72-22,59 \mathrm{~A} \times \mathrm{pT} 72-34$, $2 \mathrm{SD} \times \mathrm{pT} 72-25$, and $2 \mathrm{SD} \times \mathrm{pT} 72-45$. These transformants grew extremely slowly in the above medium for the first 2 weeks postfusion but started growing at reasonable rates (with doubling times of between 22 and $28 \mathrm{~h}$ ) after the medium was supplemented with $50 \mu \mathrm{g}$ of uridine per ml; this uridine requirement presumably reflected the nearly complete absence of mitochondrial protein synthesis and respiration in these transformants. The CAP23 cell line, a CAPr derivative of the $\mathrm{VA}_{2} \mathrm{~B}$ cell line, previously isolated and characterized in this laboratory $(31,32)$ and shown to exhibit a T-to-C transition at position 2991, one of three known sites of CAPr $^{r}$ mutations in the 16S rRNA gene of mammalian cells (26), was grown in DMEM with $10 \%$ calf serum, $3 \mu \mathrm{g}$ of 8 -azaguanine per ml, and $40 \mu \mathrm{g}$ of CAP per ml.

Myoblast culture and mitochondrion-mediated $\rho^{0} 206$ cell transformation. A mass myoblast culture was established from a muscle biopsy specimen from a patient with MERRF by a previously reported procedure (29) and used for $\rho^{0} 206$ cell transformation by cytoplast fusion, carried out as described previously (25). In particular, enucleated myoblasts were fused to $\sim 5 \times 10^{5}$ to $1 \times 10^{6} \rho^{0} 206$ cells, and transformants were isolated and maintained in DMEM supplemented with $10 \%$ dialyzed FBS and $100 \mu \mathrm{g}$ of BrdU per ml. The population doubling time (DT) of the transformants was determined by using the formula DT $=\left(t-t_{0}\right) \log 2 /\left(\log N-\log N_{0}\right)$, where $N$ is the cell number and $t$ is the time when the cells were counted.

Subcloning of MERRF transformants. One or more samples, each containing approximately $20 \rho^{0}$ cell transformants derived from myoblasts from the MERRF patient, were mixed with $10^{5} \rho^{0} 206$ cells in DMEM with 5\% FBS and $100 \mu \mathrm{g}$ of BrdU per $\mathrm{ml}$ and plated into 96 -well plates at a final cell density of 0.2 transformant and $10^{3} \rho^{0}$ cells per well. Colonies were recognized between 1 and 2 weeks after plating and transferred by trypsinization into the wells of a 24-well plate or into $3.5-\mathrm{cm}$ plates. In some experiments, as specified below, subcloning was carried out in the absence of $\rho^{0} 206$ feeder cells.

Fusion of MERRF transformant cytoplasts with MELAS transformants. A large excess $\left(\sim 5 \times 10^{5}\right.$ to $\left.1 \times 10^{6}\right)$ of cells of the MERRF transformant pT72 were enucleated by centrifugation in the presence of cytochalasin $B$ and then fused with a small number of cells $(\sim 6,000)$ of the MELAS transformant 59A or 2SD (8). The transformants were isolated in DMEM supplemented with $10 \%$ dialyzed FBS and $100 \mu \mathrm{g}$ of BrdU per $\mathrm{ml}$. In this medium, only unfused MELAS transformants and cybrids between these transformants and pT72 cytoplasts were expected to survive; residual nonenucleated pT72 cells or hybrids between these and the MELAS transformants were expected to be killed by BrdU phosphorylated by the thymidine kinase encoded in the pT72 nucleus. To identify the cybrids, the clones were screened for the presence of the MERRF mutation by PCR amplification of an mtDNA fragment encompassing the mutation, using a mismatched primer and NaeI restriction digestion, as described below. Six clones exhibiting the MERRF mutation were identified after screening 116 clones.

Fusion of CAP23 cytoplasts with 143B cells. In these experiments, a small number of CAP23 cells $(\sim 2,000$ cells) were enucleated by centrifugation in the presence of cytochalasin $B$ and then fused with a large excess of 143B cells $\left(\sim 10^{6}\right.$ cells $)$. In a first fusion experiment, 13 cybrids were isolated and maintained in DMEM with $10 \%$ dialyzed FBS in the presence of $100 \mu \mathrm{g}$ of CAP and $100 \mu \mathrm{g}$ of BrdU per ml until the time of analysis (57 to 58 days after fusion). In a second experiment, 4 cybrids were maintained in $100 \mu \mathrm{g}$ of CAP per ml until the time of analysis ( 36 days after fusion), and 12 cybrids were transferred, 31 days after fusion, to a medium containing 100 $\mu \mathrm{g}$ of BrdU per ml and either $25 \mu \mathrm{g}$ of CAP per ml (9 cybrids) 
or $25 \mu \mathrm{g}$ of CAP plus $50 \mu \mathrm{g}$ of uridine per $\mathrm{ml}$ ( 3 cybrids) and kept in these media for 5 days before analysis.

DNA analysis. Total DNA samples were prepared from unlabeled cultured cells with an Applied Biosystems 340A DNA extractor or by direct lysis in PCR buffer $(10 \mathrm{mM}$ Tris- $\mathrm{HCl}$ [pH 8.4], $50 \mathrm{mM} \mathrm{KCl}, 1 \mathrm{mM} \mathrm{MgCl}$ ) containing 100 $\mu \mathrm{g}$ of proteinase $\mathrm{K}$ per $\mathrm{ml}$ and $0.5 \%$ Tween 20 (24). Total DNA from biopsy specimens was extracted as described previously (37). For the detection of the MERRF A $\rightarrow$ G transition in the mitochondrial tRNA ${ }^{\text {Lys }}$ gene $(40,53)$ at position 8344 in the Cambridge human mtDNA sequence, an mtDNA segment which encompasses the mutation was amplified by PCR, using a mismatched primer which generated a new NaeI site over the mutated template, and then digested with NaeI (52). In particular, samples of total cell DNA from the original muscle biopsy specimen, the mass myoblast culture, the mitochondrial transformants, or 143B cells were processed in a thermal cycler (Eppendorf or Perkin-Elmer Cetus), using Taq polymerase (Promega) and oligonucleotides corresponding to the L-strand between positions 8191 and 8210 and to the $\mathrm{H}$-strand between positions 8345 and 8364 (5'-TCACTGTAAAGAGGTGC CGG; underlined nucleotides differ from the Cambridge sequence and create an NaeI site when the MERRF mutation is present) as primers. The amplified fragments were digested with NaeI in the presence of the 654-bp EcoRI-SalI fragment of pBR322 DNA as an internal marker for completion of digestion and analyzed by electrophoresis through a 5\% polyacrylamide-7 $\mathrm{M}$ urea gel for the detection and quantitation of the MERRF mutation. In some experiments, as specified below, the amplified fragments were digested with $\mathrm{NaeI}$ in the presence of the 1,075-bp XmnI-KpnI fragment of pBluescript KS+ DNA as an internal digestion marker; equal amounts of the various mixtures were then analyzed by electrophoresis through a $5 \%$ polyacrylamide gel.

In order to quantitate the proportion of mtDNA molecules carrying the MERRF mutation in a DNA sample by specific restriction enzyme digestion of the mtDNA PCR products, a mixed-template standard curve was constructed (40). For this purpose, the PCR-amplified products of the mtDNAs from the previously isolated pT1 transformant, containing in homoplasmic form the MERRF mutation, and pT5 transformant, containing in homoplasmic form the corresponding wild-type sequence (9), were cloned in the Bam HI and EcoRI sites of the pBluescript KS + vector (Stratagene), and mixtures in different ratios of the whole plasmids pKS+.pT1-1 and pKS+.pT5-2, containing the mutant and the wild-type sequence, respectively, were subjected to PCR amplification and NaeI digestion in the presence of the EcoRI-SalI fragment of pBR322 DNA mentioned above as an internal marker for completion of digestion. The products were run on a $5 \%$ polyacrylamide- $7 \mathrm{M}$ urea gel, and the proportion of digested and undigested molecules was determined by using an LKB laser densitometer after ethidium bromide staining. Figure 1a compares the mixed-template standard curve (T) thus constructed for the MERRF mutation with the mixed-product standard curve (P) constructed by mixing, in different ratios, the PCR products independently amplified from pKS+.pT1-1 and pKS+.pT5-2 and then subjecting the mixtures to restriction enzyme digestion. As shown previously (40), the T curve differs significantly from the $\mathbf{P}$ curve. This difference presumably results from the formation, during the final stages of PCR amplification, of heteroduplexes of wild-type and mutant mtDNA which are totally or partially resistant to the restriction enzyme digestion.

For the detection of the MELAS $A \rightarrow G$ transition at position 3243 in the tRNA ${ }^{\text {Leu(UUR) }}$ gene $(17,27,45)$, advantage was taken of the fact that the mutation creates an ApaI restriction

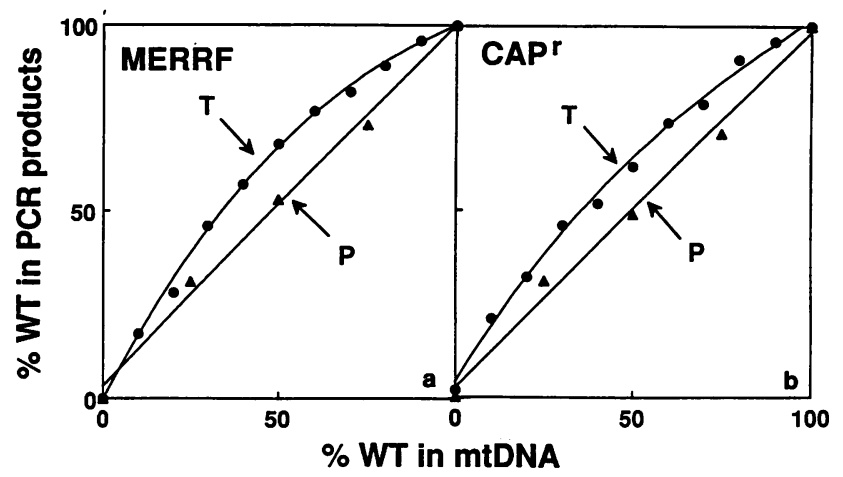

FIG. 1. (a) Standard curves for quantitation of the MERRF mutation in mtDNA. (b) Standard curves for quantitation of the CAPr mutation in mtDNA. T, mixed-template standard curve; $P$, mixedproduct standard curve; WT, wild type.

site and therefore it is possible to use ApaI digestion to monitor the presence and proportion of mutated mtDNA. For quantitation of the MELAS mutation, a mixed-template standard curve, constructed as described previously (51), was used.

For the detection of the CAPr T-to-C transition at position 2991 in the 16S rRNA gene of CAP23 mtDNA, an mtDNA fragment which encompasses the mutation was amplified by PCR with oligonucleotides corresponding to the L-strand between positions 2819 and 2838 and to the $\mathrm{H}$-strand between positions 2992 and 3016 (5-CACCATCGGGATGTCCTGA TCCGAC-3'; the underlined nucleotide differs from the Cambridge sequence and creates an AatII site when the CAPr mutation is present) as primers. The amplified fragments from the cybrids between CAP23 cytoplasts and 143B cells or from $143 \mathrm{~B}, \mathrm{VA}_{2} \mathrm{~B}$, or CAP23 cells were digested with Aat II in the presence of the 775-bp fragment (including an 8-nucleotide tail of one of the primers) of human mtDNA between positions 7626 and 8392, amplified by PCR from 143B total cell DNA, as an internal marker for completion of digestion. A portion of each digested mixture was then run through a 5\% polyacrylamide gel for the detection and densitometric quantitation of the CAPr mutation.

To correct the data for the formation of heteroduplexes of wild-type and mutant mtDNA which may be partially or totally resistant to AatII digestion during PCR amplification, a template standard curve was constructed. For this purpose, an mtDNA fragment from CAP23 cells harboring the CAP ${ }^{r}$ mutation and the corresponding mtDNA fragment from the $\mathrm{VA}_{2} \mathrm{~B}$ cell line, the parent of CAP23, were amplified by PCR, and then mixtures in different ratios of the two PCR products were digested with AatII in the presence of the internal digestion marker and analyzed as specified above. Figure $1 \mathrm{~b}$ compares the mixed-template standard curve $(T)$ thus constructed for the CAPr mutation with the mixed-product standard curve $(\mathrm{P})$ constructed by mixing, in different ratios, the PCR products independently amplified from CAP23 mtDNA and $\mathrm{VA}_{2} \mathrm{~B}$ mtDNA and then subjecting the mixtures to AatII digestion. Here too, one observes a significant difference between the $T$ and $P$ curves, which presumably reflects the presence of heteroduplexes.

Southern blot analysis of equal samples of total cell DNA digested with BamHI for quantitation of mtDNA was carried out with the entire HeLa cell mtDNA, ${ }^{32} \mathrm{P}$ labeled by random priming (15), as a probe. To correct for possible quantitative variations among different DNA samples, the same membrane was probed with a nuclear 28S rRNA gene fragment, con- 

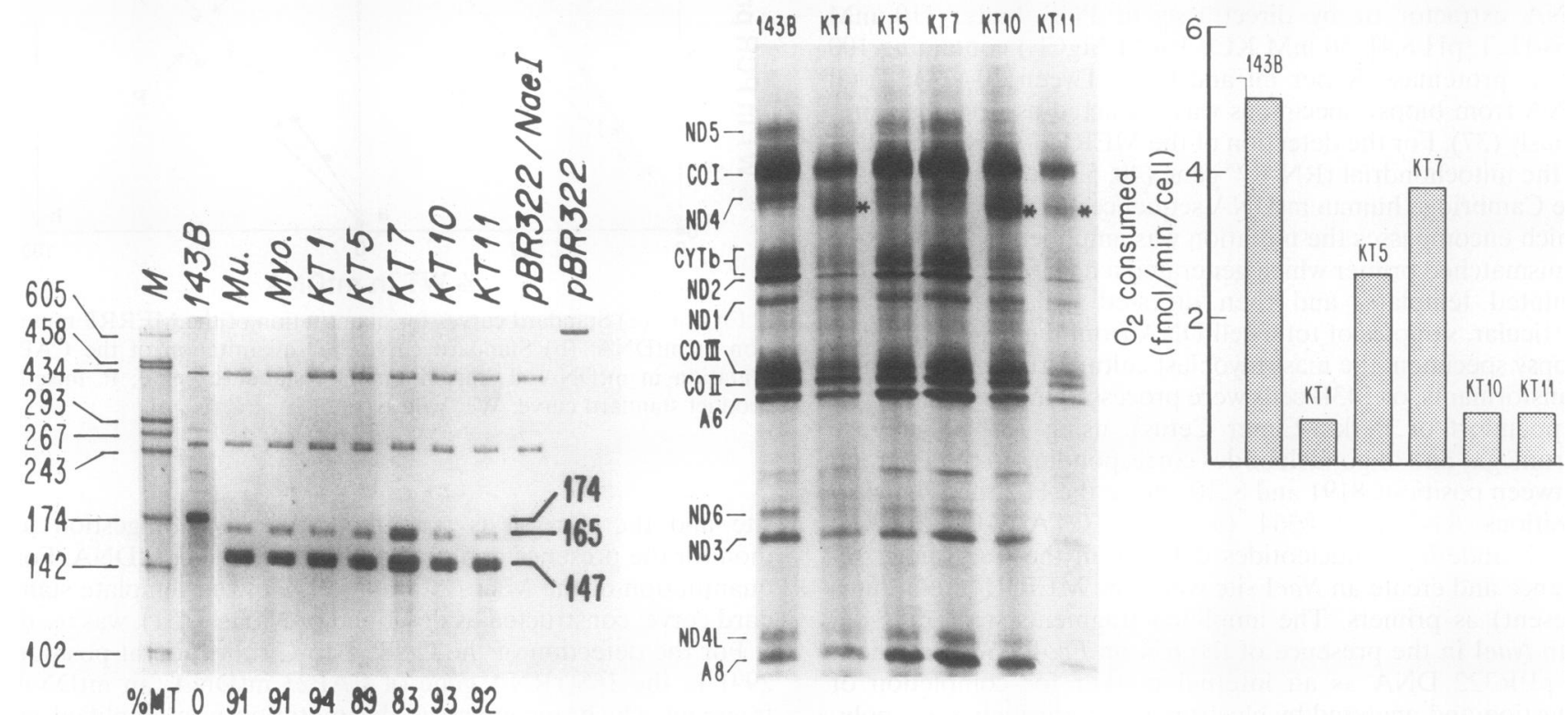

FIG. 2. Transformants obtained by mitochondrion transfer from MERRF proband myoblasts into human $\rho^{0}$ cells exhibit variable genotype and phenotype. (a) Genotype of the proband muscle (Mu) biopsy specimen, the myoblast (Myo) culture, five mitochondrial transformants, and 143B cells, analyzed by PCR amplification of total DNA with a mismatched primer and by running the PCR products on a 5\% polyacrylamide-7 M urea gel, as described in Materials and Methods. Indicated are the sizes of the uncut PCR product in the muscle, myoblast, and transformant DNA samples $(165 \mathrm{bp})$ and that of the larger fragment $(147 \mathrm{bp})$ produced by NaeI cleavage of the mutation-containing PCR product. The size of the PCR product in the proband-derived DNA samples is 9 bp smaller than that obtained in the 143B DNA sample (174 bp) because of a nonanucleotide deletion frequently present in Asian populations (22). Lane M, HaeIII-digested pBluescript KS+ DNA; lane pBR322/NaeI, fragments produced by NaeI cleavage of the EcoRI-SalI fragment of pBR322; lane pBR322, EcoRI-SalI fragment of pBR322; \%MT, percentage of mutant mtDNA. (b) Patterns of mitochondrial translation products $\left(2-\mathrm{h}\left[{ }^{35} \mathrm{~S}\right]\right.$ methionine labeling, $25 \mu \mathrm{g}$ of protein run on gel). COI, COII, and COIII, subunits I, II, and III of cytochrome $c$ oxidase, respectively; ND1, ND2, ND3, ND4, ND4L, ND5, and ND6, subunits 1, 2, 3, 4, 4L, 5, and 6 of the respiratory chain NADH dehydrogenase, respectively; $\mathrm{A} 6$ and A8, subunits 6 and 8 of the $\mathrm{H}^{+}$-ATPase, respectively; CYTb, apocytochrome $b$. The asterisks indicate abnormal translation products. (c) Rate of $\mathrm{O}_{2}$ consumption in the five transformants and, for comparison, in 143B cells. The times after mitochondrial transfer that the mtDNA analysis was performed were 72 days (KT1), 60 days (KT5), 60 days (KT7), 27 days (KT10), and 17 days (KT11).

structed by PCR amplification with oligonucleotides corresponding to positions 1503 to 1522 and 1981 to 2000 in the $28 \mathrm{~S}$ rRNA gene (16), purified on an agarose gel, and ${ }^{32} \mathrm{P}$ labeled by random priming. Radioactivity was quantitated by laser densitometry of the autoradiograms.

Mitochondrial protein synthesis and $\mathrm{O}_{2}$ consumption analysis. Cultures of individual transformants or 143B cells $(\sim 2 \times$ $10^{5}$ cells) were labeled with $\left[{ }^{35} \mathrm{~S}\right]$ methionine $(>800 \mathrm{Ci} / \mathrm{mmol}$, $25 \mu \mathrm{Ci} / \mathrm{ml}$ ) for $2 \mathrm{~h}$ in the presence of $100 \mu \mathrm{g}$ of emetine per $\mathrm{ml}$, and the samples were then washed, trypsinized, lysed with $1 \%$ sodium dodecyl sulfate (SDS), and run on SDS-exponential polyacrylamide gradient gels, as described previously (9). $\mathrm{O}_{2}$ consumption measurements were made as detailed earlier (25).

\section{RESULTS}

Isolation of heteroplasmic mitochondrial transformants carrying the MERRF tRNA ${ }^{\text {Lys }}$ mutation. The proband from which the myoblast cultures were derived was from a 25 -yearold Japanese male with characteristic symptoms of MERRF syndrome, including myoclonic epilepsy, ataxia, dementia, and mitochondrial myopathy with ragged red fibers. His mother exhibited similar but milder symptoms. Analysis of DNA from muscle biopsy specimens showed the presence of the mitochondrial tRNA ${ }^{\text {Lys }}$ mutation in both the patient and the mother (52). A mass myoblast culture was established from a muscle specimen of the proband, and myoblast-derived cytoplasts were fused to a large excess of $\rho^{0} 206$ cells. Eleven presumptive mitochondrial transformants were isolated by growing the cell fusion mixtures in medium containing BrdU and lacking uridine (25). As shown in Fig. 2a, the muscle specimen and the mass myoblast culture exhibited the tRNA ${ }^{\text {Lys }}$ mutation in $\sim 91 \%$ of the mtDNA molecules. Nine of the 11 transformants were found to contain more than $90 \%$ mutant mtDNA, while the other 2 (KT5 and KT7) contained between 80 and $90 \%$ mutant mtDNA. These two transformants and three of the others (KT1, KT10, and KT11) were chosen for further study and maintained in continuous culture over an 8- to 9-month period. During this time, in KT1, KT10, and KT11, the wild-type mtDNA level remained constant at 5 to $8 \%$, whereas in KT5 and KT7, the wild-type mtDNA level declined fairly rapidly from 15 and $17 \%$, respectively, 1 to 2 months after isolation, to $\sim 9 \%$, and slowly reached a level of 6 to $7 \%$ after 7 months.

Figure $2 \mathrm{~b}$ displays the mitochondrial translation products of the transformants labeled with $\left[{ }^{35} \mathrm{~S}\right]$ methionine for $2 \mathrm{~h}$ in the presence of $100 \mu \mathrm{g}$ of emetine per $\mathrm{ml} 16$ to 17 weeks after 

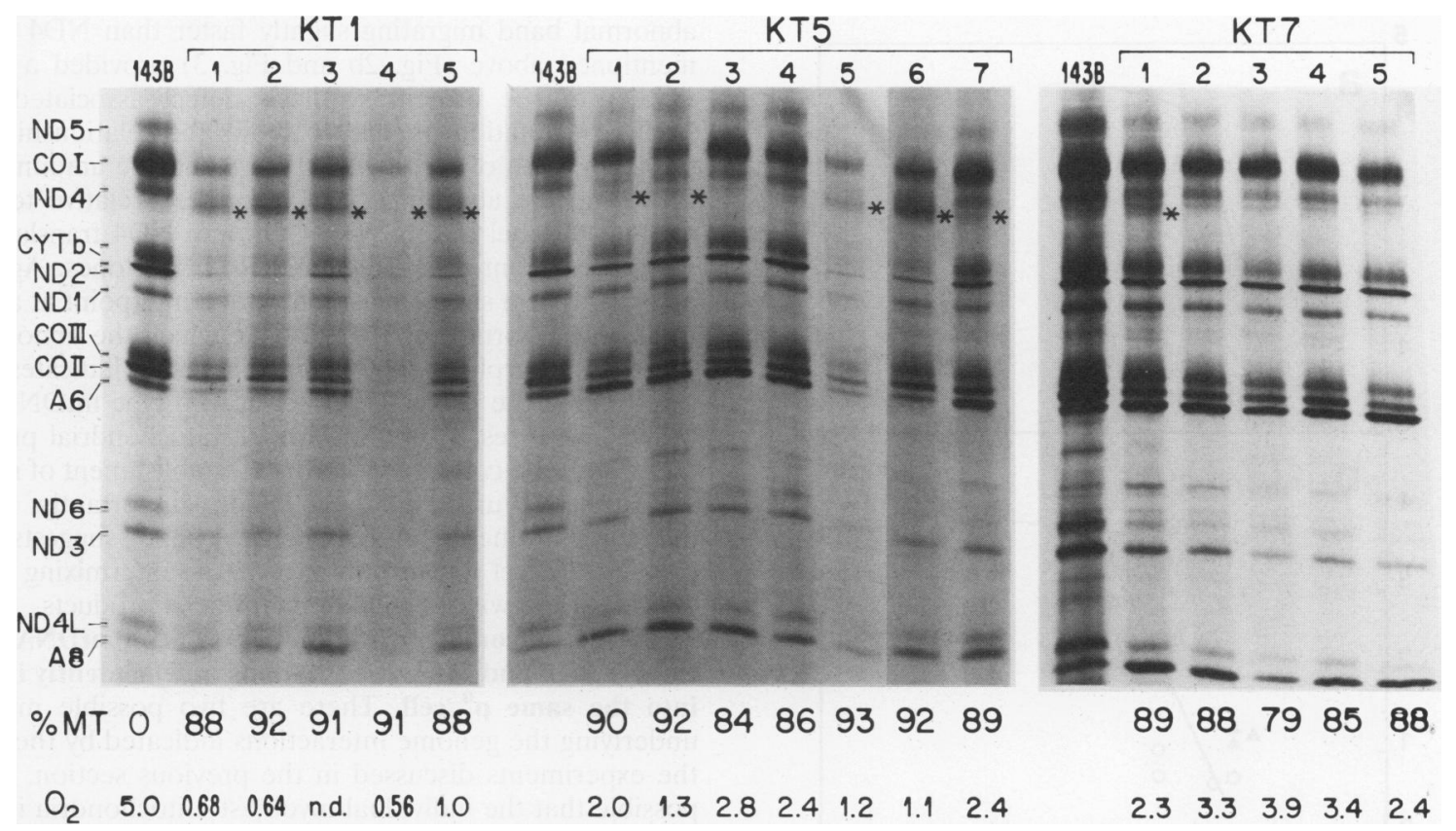

FIG. 3. Genotype and phenotype of subclones of individual MERRF transformants. The KT1, KT5, and KT7 transformants were subcloned, respectively, 8 weeks, 8 and 14 weeks, and 14 weeks after mitochondrion transfer, and five subclones of KT1 and KT7 and seven subclones of KT5 ( 1 to 5 from the second subcloning experiment and 6 and 7 from the first subcloning experiment) were analyzed for genotype, $\mathrm{O}_{2}$ consumption, and mitochondrial protein synthesis (2-h labeling, $25 \mu \mathrm{g}$ of protein run on gel). Except for the subclones of KT1 and subclones 6 and 7 of KT5, all subclones were isolated in the presence of $\rho^{0} 206$ feeder cells. Below the fluorograms are indicated the percent mutant (MT) mtDNA content and the $\mathrm{O}_{2}$ consumption (in femtomoles per minute per cell) of the individual cell lines. n.d., not determined. See the legend to Fig. $2 b$ for other details.

fusion. Considerable variability in the labeling of the mtDNAencoded proteins was observed among the transformants. Transformants KT1, KT10, and KT11 showed various decreases in protein labeling relative to the 143B parental cells, as well as the presence of an abnormal translation product migrating faster than ND4 (asterisks in Fig. 2b) previously identified as characteristic of MERRF patient myoblasts $(5,9)$ and $\rho^{0}$ transformants derived therefrom (9). By contrast, the level of labeling and the pattern of the mitochondrial translation products of KT5 and KT7, which at the time of analysis had a mutant mtDNA content of 91 and $87 \%$, respectively, appeared to be fairly similar to those of $143 \mathrm{~B}$ cells, with a small amount of the abnormal band. Correspondingly, the rate of $\mathrm{O}_{2}$ consumption, analyzed 15 to 17 weeks after fusion, was strongly decreased in KT1, KT10, and KT11 ( $\leq 0.7 \mathrm{fmol} / \mathrm{min} /$ cell), moderately decreased in KT5 $(2.5 \mathrm{fmol} / \mathrm{min} / \mathrm{cell})$, and only slightly reduced in $\mathrm{KT} 7(3.8 \mathrm{fmol} / \mathrm{min} / \mathrm{cell})$ compared with the rate in 143B cells (Fig. 2c).

Subcloning of MERRF transformants. In order to investigate the intercellular heterogeneity in genotype and phenotype of the transformants, five to seven subclones were isolated, as described in Materials and Methods, from each of the KT1, KT5, and KT7 clones, at times corresponding, respectively, to 8,8 and 14, and 14 weeks after their isolation. As shown in Fig. 3 , the individual subclones from each transformant exhibited relatively little variation in the proportion of wild-type mtDNA, with its average approaching that of the parental clone (10 versus $7 \%$ in KT1, 9 versus $12 \%$ and 11 versus $9 \%$ in KT5, and 14 versus $14 \%$ in KT7). The KT1 subclones all showed clearly reduced labeling of the mitochondrial translation products, with a relatively pronounced abnormal band (asterisks) (barely visible for clone 4 because of the extreme decrease in protein synthesis), and strongly decreased $\mathrm{O}_{2}$ consumption (Fig. 3). The KT5 subclones showed heterogeneity in the phenotypic expression of the mutation; two, subclones 5 and 6 , exhibited a variable reduction in labeling of the mtDNA-encoded polypeptides, with a relatively large amount of the abnormal band and a strong reduction in $\mathrm{O}_{2}$ consumption, while the others showed a normal or near-normal level of labeling, with a small or negligible amount of abnormal band and a substantial to strong decrease in $\mathrm{O}_{2}$ consumption. The K7 subclones, except for subclone 1, which exhibited a small amount of the characteristic abnormal band recognizable for its diffuse appearance (asterisk), showed a normal mitochondrial translation pattern, although with somewhat decreased labeling of the protein products; furthermore, they exhibited a variable reduction in $\mathrm{O}_{2}$ consumption (Fig. 3).

Complementation of defects caused by the MERRF mutation by a small minority of wild-type mtDNA. The data discussed in the two previous sections indicated that wild-type mtDNA, even when present in relatively small amounts, can exert a protective effect against manifestation of the MERRF mutation-associated respiration defect. Figure 4a summarizes the relationship between the proportion of wild-type mtDNA and respiratory capacity in different MERRF transformants isolated in the present work and tested at various times after their isolation. The diagram clearly illustrates the existence of a sharp transition, with a mid-point at a wild-type mtDNA proportion of $\sim 8 \%$, in the ability of wild-type mtDNA to protect against manifestation of the respiration defect, with full protection by $\sim 10 \%$ wild-type mtDNA (Fig. 4a). During prolonged growth of the KT7 transformant, while the percentage of wild-type mtDNA decreased from $\sim 17$ to $\sim 7.5 \%$, passing through the transition in its protective capacity men- 


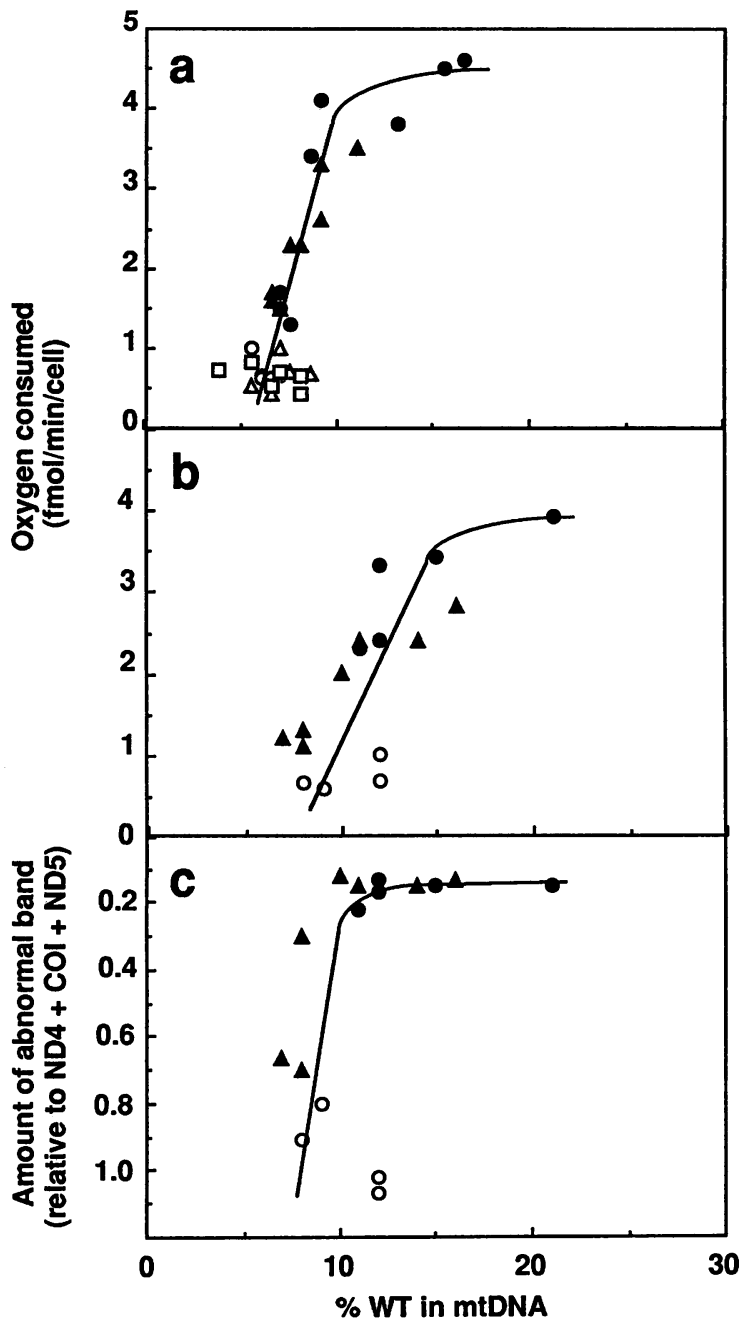

FIG. 4. A small minority of wild-type mtDNA can prevent the defective respiration ( $a$ and $b$ ) and protein synthesis (c) caused by the MERRF mutation in different heteroplasmic transformants and their subclones. (a and b) Relationship between proportion of wild-type mtDNA and respiratory capacity in different heteroplasmic mitochondrial transformants (KT1, KT5, KT7, KT10, and KT11) at various times after mitochondrion transfer (a) and in the KT1, KT5, and KT7 subclones (b). (c) Relationship between proportion of wild-type mtDNA and amount of radioactivity in the abnormal protein band, expressed relative to the total amount of label in the ND5, COI, and ND4 translation products, in different KT1, KT5, and KT7 subclones. Each symbol represents a different subclone. WT, wild type.

tioned above, no significant change was observed in the mtDNA content per cell (data not shown). This indicates that the threshold in wild-type mtDNA proportion above which this DNA protects against the phenotypic effects of the mutation reflects an equivalent sharp threshold in the absolute amount of wild-type mtDNA. The data for the KT1, KT5, and KT7 subclones also show a similar protective effect of wild-type mtDNA against the phenotypic expression of the MERRF mutation, but the mid-point transition is displaced towards a $12 \%$ proportion of wild-type mtDNA for unknown reasons (Fig. 4b).

In order to investigate whether the protective effect of wild-type mtDNA involved an interaction of the wild-type and mutant gene products, advantage was taken of the fact that the abnormal band migrating slightly faster than ND4 which was mentioned above (Fig. $2 \mathrm{~b}$ and Fig. 3) provided a molecular marker of the protein synthesis defect associated with the MERRF mutation. Figure $4 \mathrm{c}$ shows the relationship between the proportion of wild-type mtDNA and the amount of radioactivity in the abnormal band, expressed relative to the total amount of label in the ND5, COI, and ND4 translation products, in different KT1, KT5, and KT7 subclones. Again, there appears to be a sharp transition, with a mid-point at a wild-type mtDNA proportion of $\sim 9 \%$, above which the abnormal band decreases sharply in amount. This result indicates that the threshold in the protective effect of wild-type mtDNA involves primarily the restoration of normal mitochondrial protein synthesis and, as a consequence, the re-establishment of respiratory competence. Furthermore, and more importantly, the disappearance of the abnormal band strongly suggests that the protective effect depends in part on the intermixing and cooperation of the wild-type and mutant gene products.

Absence of complementation between two mtDNAs carrying the MERRF and MELAS mutations independently introduced into the same $\rho^{0}$ cell. There are two possible mechanisms underlying the genome interactions indicated by the results of the experiments discussed in the previous section. First, it is possible that the individual myoblast mitochondria introduced into $\rho^{0} 206$ cells contained both wild-type and mutant genomes as a result of the original mutation event and that this intramitochondrial heteroplasmy was maintained in the transformants. The second possibility is that fusion of the organelles produced or enhanced the intermixing and interactions of the two genomes. In order to test directly the capacity of mitochondrial genomes carried in originally distinct organelles to interact with each other in the $\rho^{0}$ transformants, advantage was taken of the ability to independently introduce mitochondria carrying mtDNA with the MERRF mutation in the tRNA ${ }^{\text {Lys }}$ gene and mitochondria carrying mtDNA with the MELAS mutation in the tRNA ${ }^{\mathrm{Leu}(U \mathrm{UR})}$ gene into the same $\rho^{0}$ cell. The results presented in the previous section and earlier observations (8) strongly suggested that the two mutations are recessive and therefore susceptible to complementation by the products of wild-type genes if there are interactions between the mutant and the wild-type genomes.

Two $\rho^{0} 206$ transformants, 59A and 2SD, derived from two genetically unrelated MELAS patients (8), were fused with an excess of cytoplasts from the $\rho^{0} 701.2 \mathrm{a}$ transformant pT72, derived from an MERRF patient (9), and 116 clones were isolated from 12 96-microwell plates, as detailed in Materials and Methods. Screening of the 116 clones for the MERRF mutation led to the identification of 6 positive clones. The very low yield of such clones substantively excluded the possibility that they represented mixed clones. Figures $5 \mathrm{a}$ and $\mathrm{b}$ show the analysis of the MERRF and MELAS mutations, carried out by PCR amplification and NaeI and ApaI digestion, respectively, in the parental lines (pT72, 59A, and 2SD), in the six two-step cybrids $(59 \mathrm{~A} \times \mathrm{pT} 72-10 \mathrm{~A}, 59 \mathrm{~A} \times \mathrm{pT} 72-10 \mathrm{~B}, 2 \mathrm{SD} \times \mathrm{pT} 72-24$, $59 \mathrm{~A} \times \mathrm{pT72}-22,59 \mathrm{~A} \times \mathrm{pT} 72-34,2 \mathrm{SD} \times \mathrm{pT} 72-25$, and $2 \mathrm{SD} \times$ pT72-45), and in 143B cells. pT72 mtDNA exhibited only the MERRF mutation, while the mtDNA from 59A and 25D cells carried only the MELAS mutation. Five of the six two-step cybrid clones, which were analyzed 42 to 99 days after fusion, exhibited both the MELAS and the MERRF mutations in various proportions. One clone $(59 \mathrm{~A} \times \mathrm{pT} 72-10)$, which was analyzed at two different times after fusion, 65 days (10A) and 114 days (10B), on the contrary, surprisingly showed only the MERRF mutation at both times. Whether this clone arose from fusion of an MERRF mutation-containing cytoplast with a wild-type cell present in the MELAS transformant popula- 

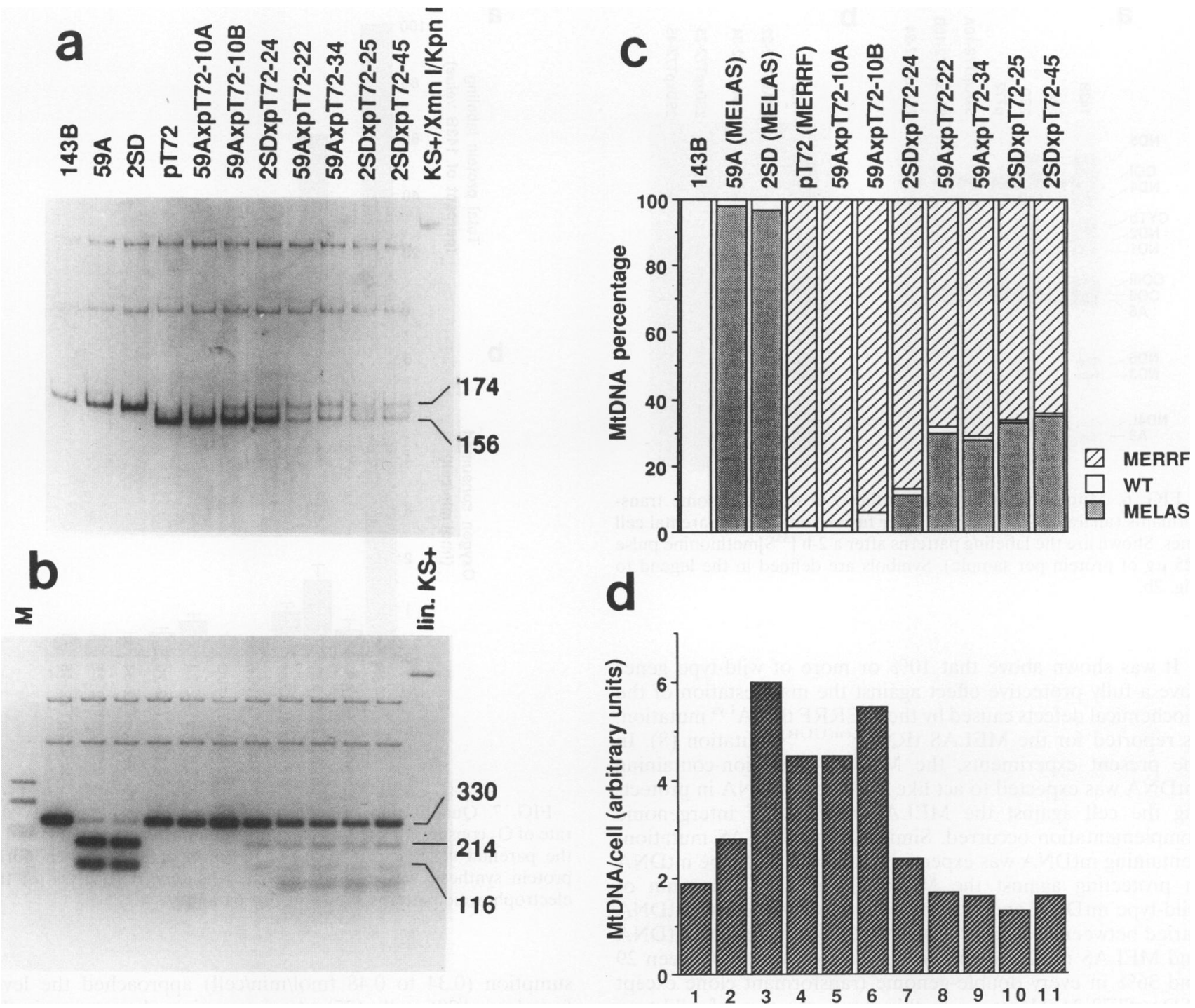

FIG. 5. Genotype of $\rho^{0} 206$ cells transformed sequentially with MELAS mutation-containing and MERRF mutation-containing mitochondria. (a and b) Detection of the MERRF and MELAS mutations in the parental cell lines, in 143B cells, and in the double-genome transformants (analyzed 42 to 99 days after fusion). (a) The MERRF mutation was analyzed, as described in Materials and Methods, by running the PCR products on a $5 \%$ polyacrylamide gel in the presence of the 1,075-bp XmnI-KpnI fragment of pBluescript KS+ DNA as an internal digestion marker. The wild-type PCR product from the DNA of transformants 59A, 2SD, and pT72 exhibited the same size (174 bp) as the 143B-derived PCR product. Lane KS $+/ \mathrm{Xmn} \mathrm{I} / \mathrm{Kpn} \mathrm{I}$, a fragment produced by XmnI-KpnI cleavage of pBluescript KS+ DNA. (b) The MELAS mutation was analyzed as described by Yoneda et al. (51). The expected sizes of the PCR product (330 bp) and of the fragments produced by ApaI digestion of the MELAS mutation-containing PCR product (214 and $116 \mathrm{bp}$ ) are indicated. lin.KS+, KS+ DNA linearized with XmnI, added as an internal marker for completion of digestion. Lane M, HaeIII-digested pBluescript KS+ DNA. (c) Percentages of MERRF mtDNA, MELAS mtDNA, and wild-type (WT) mtDNA in the double-genome transformants and in the parental cell lines, estimated from densitometric analysis of the electrophoretic patterns shown in panels a and b by using the standard curves shown in Fig. 1 and in Yoneda et al. (51). (d) Amounts of mtDNA per cell in the double-genome transformants and in the parental cell lines.

tion or from a genotype shift of this double-genome transformant towards the MERRF genotype is not known.

Figure 5c shows the percentages of MERRF mtDNA, MELAS mtDNA, and wild-type mtDNA observed in the above transformants and in the parent cell lines. The MERRF mtDNA content varied among the five double-genome transformant clones between $\sim 64$ and $\sim 87 \%$, the MELAS mtDNA content varied between $\sim 12$ and $\sim 35 \%$, and the wild-type mtDNA content varied between 0 and $\sim 2 \%$. Figure $5 \mathrm{~d}$ shows the relative mtDNA amount per cell in the transformants and in the parental cell lines. The mtDNA content per cell in the
59A parental line and in the double-genome transformants was fairly similar to the level in 143B cells. By contrast, the 2SD and pT72 parental lines and the $59 \mathrm{~A} \times \mathrm{pT} 72-10 \mathrm{~A}$ and $59 \mathrm{~A} \times \mathrm{pT} 72-10 \mathrm{~B}$ transformants exhibited a large increase $(245$ to $325 \%$ ) in mtDNA content relative to the 143B cells. This increase presumably reflects a compensatory phenomenon stimulated by the presence of functionally defective mitochondria. The fact that this increase in mtDNA content did not persist in the double-genome transformants derived from 2SD and pT72 may indicate a change in nuclear gene content and/or activity resulting from the fusion event. 

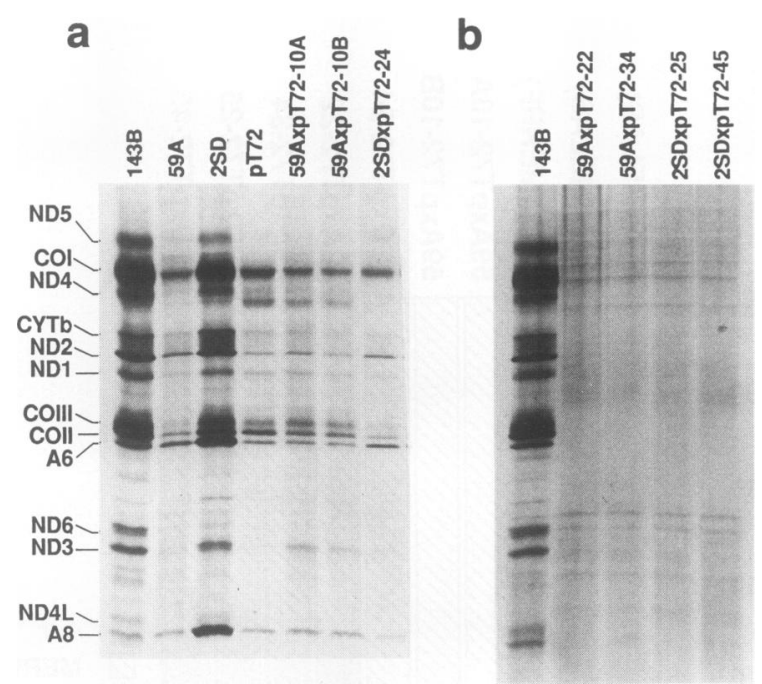

FIG. 6. Mitochondrial protein synthesis of double-genome transformants (analyzed 42 to 99 days after fusion) and of the parental cell lines. Shown are the labeling patterns after a $2-\mathrm{h}\left[{ }^{35} \mathrm{~S}\right]$ methionine pulse ( $25 \mu \mathrm{g}$ of protein per sample). Symbols are defined in the legend to Fig. $2 b$.

It was shown above that $10 \%$ or more of wild-type genes have a fully protective effect against the manifestation of the biochemical defects caused by the MERRF tRNA ${ }^{\text {Lys }}$ mutation, as reported for the MELAS tRNA ${ }^{\text {Leu(UUR) }}$ mutation (8). In the present experiments, the MERRF mutation-containing mtDNA was expected to act like wild-type mtDNA in protecting the cell against the MELAS mutation if intergenome complementation occurred. Similarly, the MELAS mutationcontaining mtDNA was expected to act like wild-type mtDNA in protecting against the MERRF mutation. The sum of wild-type mtDNA and MERRF mutation-containing mtDNA varied between 65 and $72 \%$ and the sum of wild-type mtDNA and MELAS mutation-containing mtDNA varied between 29 and $36 \%$ in every double-genome transformant clone except $2 \mathrm{SD} \times \mathrm{pT} 72-24$. However, in this clone, the sum of wild-type mtDNA and MELAS mutation-containing mtDNA was $14 \%$, i.e., above the threshold for protection against the phenotypic effect of the MERRF mutation. Therefore, it was expected that if there was genome interaction, there would be reciprocal complementation between mtDNA containing the MERRF or the MELAS mutation and mtDNA lacking that mutation in all five double-genome transformants. On the contrary, it is clear from Fig. 6 that the labeling of the mitochondrial translation products in the double-genome transformants (measured 42 to 99 days after fusion) during a $2-\mathrm{h}\left[{ }^{35} \mathrm{~S}\right]$ methionine pulse was lower than the labeling in the parental cell lines. Particularly striking is the marginal labeling of the mitochondrial translation products in the transformants $59 \mathrm{~A} \times \mathrm{pT} 72-22,59 \mathrm{~A} \times$ pT72-34, 2SD $\times$ pT72-25, and 2SD $\times$ pT72-45 (Fig. 6b). Densitometric quantitation of the labeling of the mtDNA-encoded polypeptides in the four double-genome transformants mentioned above showed a level of about $1 \%$ of the value observed in $143 \mathrm{~B}$ cells (Fig. 7a). In agreement with the protein labeling data, there was no recovery of respiration capacity in any of the double-genome transformants, their rates of $\mathrm{O}_{2}$ consumption (measured within a few days from the protein synthesis analysis) varying between 6.8 and $14 \%$ of that in 143B cells (Fig. $7 b)$. In particular, in the four transformants with a negligible level of mitochondrial protein synthesis, the rate of $\mathrm{O}_{2}$ con-
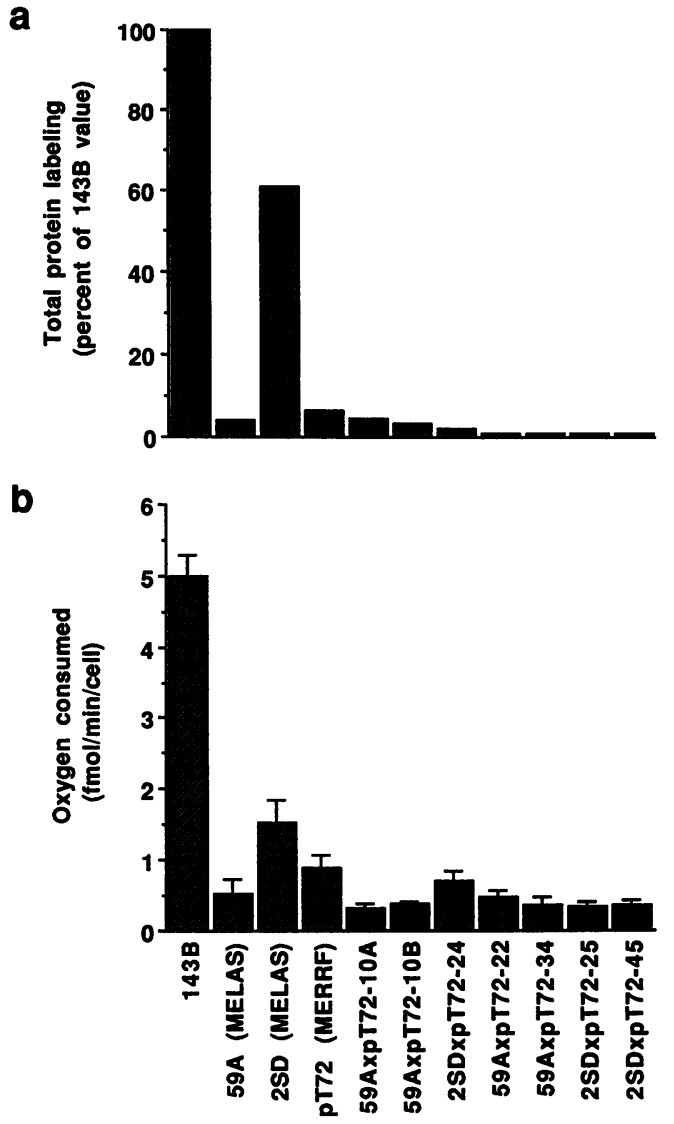

FIG. 7. Quantitation of mitochondrial protein synthesis (a) and rate of $\mathrm{O}_{2}$ consumption (b) in the double-genome transformants and in the parental cell lines. In panel a, the level of total mitochondrial protein synthesis was estimated from densitometric analysis of the electrophoretic patterns shown in Fig. 6a and b.

sumption ( 0.34 to $0.48 \mathrm{fmol} / \mathrm{min} /$ cell) approached the level found in $\rho^{0} 206$ cells (25). An interesting observation is the relatively high level of labeling of the mitochondrial translation products $\left(\sim 60 \%\right.$ of the level in 143B) and rate of $\mathrm{O}_{2}$ consumption $(\sim 30 \%$ of the level in 143B) in the parental line 2SD, which had the highest mtDNA content $(\sim 3.2$ times that in 143B). A comparison of the data in Fig. $5 \mathrm{c}$ and d with those in Fig. 7a and $b$ shows that the lower labeling of the mitochondrial translation products and lower rate of $\mathrm{O}_{2}$ consumption in the double-genome transformants compared with the parental lines correlate to a good extent with a decrease in mtDNA content.

Lack of complementation between exogenous CAPr mtDNA and resident CAP $^{s}$ mtDNA in 143B cells. The apparent absence of complementation between the MERRF and MELAS mutations independently introduced into $\rho^{0} 206$ cells, indicated by the experiments discussed in the previous section, was at variance with previously reported findings (35). These findings had been interpreted to suggest that HT1080 mtDNA, carrying a 16S rRNA gene mutation that conferred CAP resistance of mitochondrial protein synthesis on the cells, allowed the synthesis of a HeLa cell mtDNA-encoded variant ND3 polypeptide (originally named MV2 and subsequently renamed ND3' on the basis of the functional identification of the ND3 gene [9]) in the presence of CAP after introduction by cybrid or hybrid fusion into HeLa cells. This interpretation 
implied an interaction of $\mathrm{CAP}^{\mathrm{r}}$ ribosomes from $\mathrm{HT} 1080$ cell mitochondria with mRNA from HeLa cell mitochondria. The presence of the variant ND3' polypeptide in HeLa cells has been correlated with a mutation in the ND3 gene that converts an asparagine codon to an aspartic acid codon, and its faster electrophoretic mobility compared with that of the normal ND3 polypeptide has been interpreted to result from either proteolytic digestion, the loss of a potential glycosylation site, or the addition of a charge group (34). In order to verify the occurrence of interactions between the products of CAP ${ }^{\mathrm{r}}$ and $\mathrm{CAP}^{\mathrm{s}}$ mtDNAs carried in originally distinct organelles in the same 143B nuclear background of the double-genome transformants investigated here, cybrids were constructed between cytoplasts from CAP23, a derivative of the human cell line $\mathrm{VA}_{2} \mathrm{~B}$, which carries an mtDNA mutation in the 16S rRNA gene conferring CAP resistance $(26,31)$, and the CAP ${ }^{\mathrm{s}} 143 \mathrm{~B}$ cell line. A favorable situation in these experiments was the fact that CAP23 exhibits the same ND3 polymorphism described for HeLa cells and that 143B cells synthesize the normal ND3 gene product.

Two fusion experiments were carried out between cytoplasts from CAP23 cells and a large excess of $143 \mathrm{~B}$ cells. Figures 8a and $b$ show the analysis of the CAP ${ }^{r}$ mutation by PCR amplification and AatII digestion in the parental cell lines $143 \mathrm{~B}, \mathrm{VA}_{2} \mathrm{~B}$ (the parent of CAP23), and CAP23 and in the cybrids obtained by fusion of CAP 23 cytoplasts and 143B cells in the first and second fusion experiments. The 143B and $\mathrm{VA}_{2} \mathrm{~B}$ cells exhibited $100 \%$ wild-type mtDNA, while CAP23 cells exhibited nearly homoplasmic (89\%) mutant mtDNA. All 13 cybrids isolated in the first experiment, which had been maintained for 57 or 58 days in the presence of $100 \mu \mathrm{g}$ of CAP per $\mathrm{ml}$, exhibited nearly homoplasmic (83 to $91 \%$; average, $89 \%$ ) mutant mtDNA (Fig. 8a). By contrast, the 16 cybrids isolated in the second experiment, which had been kept in medium containing $100 \mu \mathrm{g}$ of CAP per ml for 36 days or maintained in this medium for 31 days and then transferred to a medium containing $25 \mu \mathrm{g}$ of CAP or $25 \mu \mathrm{g}$ of CAP plus 50 $\mu \mathrm{g}$ of uridine per $\mathrm{ml}$ for 5 days, exhibited lower proportions of $\mathrm{CAP}^{\mathrm{r}} \mathrm{mtDNA}$, from 9 to $53 \%$ (average, 27\%). Figure $8 \mathrm{~b}$ shows the genotype analysis of the parental cell lines $143 \mathrm{~B}, \mathrm{VA}_{2} \mathrm{~B}$, and CAP23 and of eight cybrids with various proportions (between 10 and $89 \%$ ) of CAPr mtDNA, chosen from those isolated in the first and second fusion experiments.

Figure $8 \mathrm{c}$ shows the pattern of mitochondrial protein synthesis after a 2-h exposure of the cells to $\left[{ }^{35} \mathrm{~S}\right]$ methionine in the absence and presence of $100 \mu \mathrm{g}$ of CAP per $\mathrm{ml}$ in the parental lines and in six of the eight cybrid clones. The mitochondrial translation patterns observed in the absence of CAP in 143B cells on one side and in $\mathrm{VA}_{2} \mathrm{~B}$ and CAP23 cells on the other were identical except for the exclusive presence of the ND3 normal gene product in 143B cells and for a greatly reduced amount of the ND3 polypeptide and a predominant amount of the variant $\mathrm{ND}^{\prime}$ product in $\mathrm{VA}_{2} \mathrm{~B}$ and CAP23 cells. The coexistence of a small amount of the ND3' variant polypeptide with a prevalent normal ND3 product had been reported previously for HeLa cells (35). Also to be noticed is the fact that the labeling of the mitochondrial translation products in CAP23 cells was significantly reduced compared with that in either 143B cells (by $25 \%$ ) or $\mathrm{VA}_{2} \mathrm{~B}$ cells (by $39 \%$ ), in agreement with earlier observations (50). Protein synthesis was nearly completely sensitive ( 97 to $98 \%$ ) to $100 \mu \mathrm{g}$ of CAP per $\mathrm{ml}$ in $143 \mathrm{~B}$ and $\mathrm{VA}_{2} \mathrm{~B}$ cells and $85 \%$ resistant to the drug in CAP23 cells.

Two cybrids ( 5 and 16$)$ with strongly predominant (89 and $85 \%$, respectively) CAP $^{r}$ mtDNA exhibited nearly complete resistance of their protein synthesis to CAP. By contrast, mitochondrial translation was nearly completely sensitive to CAP in two cybrids (36 and 43) with minor proportions of CAP $^{\mathrm{r}}$ mtDNA (12 and $10 \%$, respectively). Two cybrids (35 and 39 ) with intermediate proportions (59 and $61 \%$, respectively) of CAPr mtDNA exhibited intermediate levels of resistance of their protein synthesis to CAP. After correction of the protein synthesis data for the double-genome transformants for the difference in protein labeling between CAP23 cells in the presence of CAP and $\mathrm{VA}_{2} \mathrm{~B}$ cells in the absence of CAP, there is a reasonably good proportionality between the percentage of protein synthesis that is resistant to CAP and the percentage of CAP $^{r}$ mtDNA (Fig. 8d, solid circles and solid line), in agreement with the assumption of genetic independence of the CAP23-derived and 143B-derived mitochondria. If no correction is applied to the protein synthesis data, the line best fitting the data (dashed line in Fig. 8d) becomes more pronouncedly curved, as would be expected if there were at least partial interactions between the CAP ${ }^{\mathrm{r}}$ and $\mathrm{CAP}^{\mathrm{s}}$ genomes, with the latter being dominant. However, a dominance of the CAP allele would be in contrast to the available evidence from bacterial systems indicating that the CAP ribosomes are not "frozen" by CAP on the polysomes and are therefore not expected to block the passage of the resistant ones (18); also, the well-documented isolation of CAPr mutants of Saccharomyces cerevisiae $(4,7)$ and mammalian cells $(44,48)$ under selective conditions, which would require the initial expression of single mutant mtDNA molecules mixed with wild-type molecules, argues strongly against a dominance of the CAP allele. Therefore, the data are most consistent with the conclusion that the CAPr and CAPs ${ }^{\mathrm{s}}$ genomes in these cybrids are phenotypically independent.

Additional evidence in favor of the above conclusion was provided by analysis of the expression, in the absence and presence of CAP, of the normal ND3 gene product and ND3' variant product in the cybrids (Fig. 8c). In fact, the two cybrids with strongly predominant CAP ${ }^{\mathrm{r}}$ mDNA (5 and 16) exhibited a prominent ND3' band and a weak ND3 band in both the absence and the presence of CAP. It seems very likely that this weak ND3 band derives from the mitochondria containing wild-type mtDNA in heteroplasmic form transferred with the CAP23 cytoplasts. Conversely, the two cybrids with minor proportions of $\mathrm{CAP}^{\mathrm{r}}$ mtDNA (36 and 43) exhibited a prominent ND3 band in the absence of CAP and only a trace of this band in the presence of CAP; a very weak ND3' band was visible in these two cybrids in both the absence and the presence of the drug. In the two cybrids with intermediate proportions of CAPr ${ }^{\mathrm{r}}$ mDNA (35 and 39), the protein labeling pattern in the absence of CAP showed a fairly strong ND3 band which was markedly reduced $(\sim 88 \%)$ in the presence of CAP and a weaker ND3' band which was only slightly affected $(\sim 20 \%)$ by exposure of the cells to the drug. This result was consistent with the phenotypic independence of the CAPr and $\mathrm{CAP}^{\mathrm{s}}$ genomes in the cybrids. The fact that the labeling of the ND3' band in the latter experiments (ND3'/[ND3 + ND3'] $15 \%$ ) was lower than expected from the proportion of $\mathrm{CAP}^{\mathrm{r}}$ mtDNA (59 to $61 \%$ ) is presumably due at least in part to the lower protein-synthetic capacity of the CAP23 mitochondria.

\section{DISCUSSION}

The present article has addressed fundamental questions of mammalian mitochondrial genetics, namely, whether mutant and wild-type mtDNA molecules can interact with each other within a cell and whether the distribution of the two types of mtDNA molecules among mitochondria can influence this capacity. Two different situations were investigated, one in- 


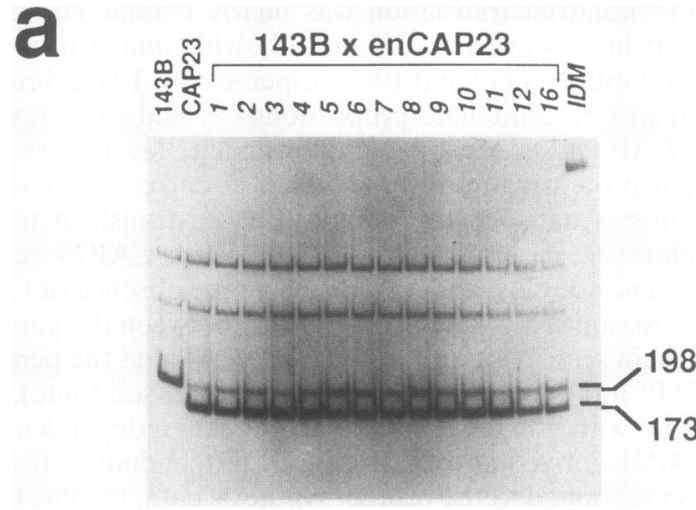

b
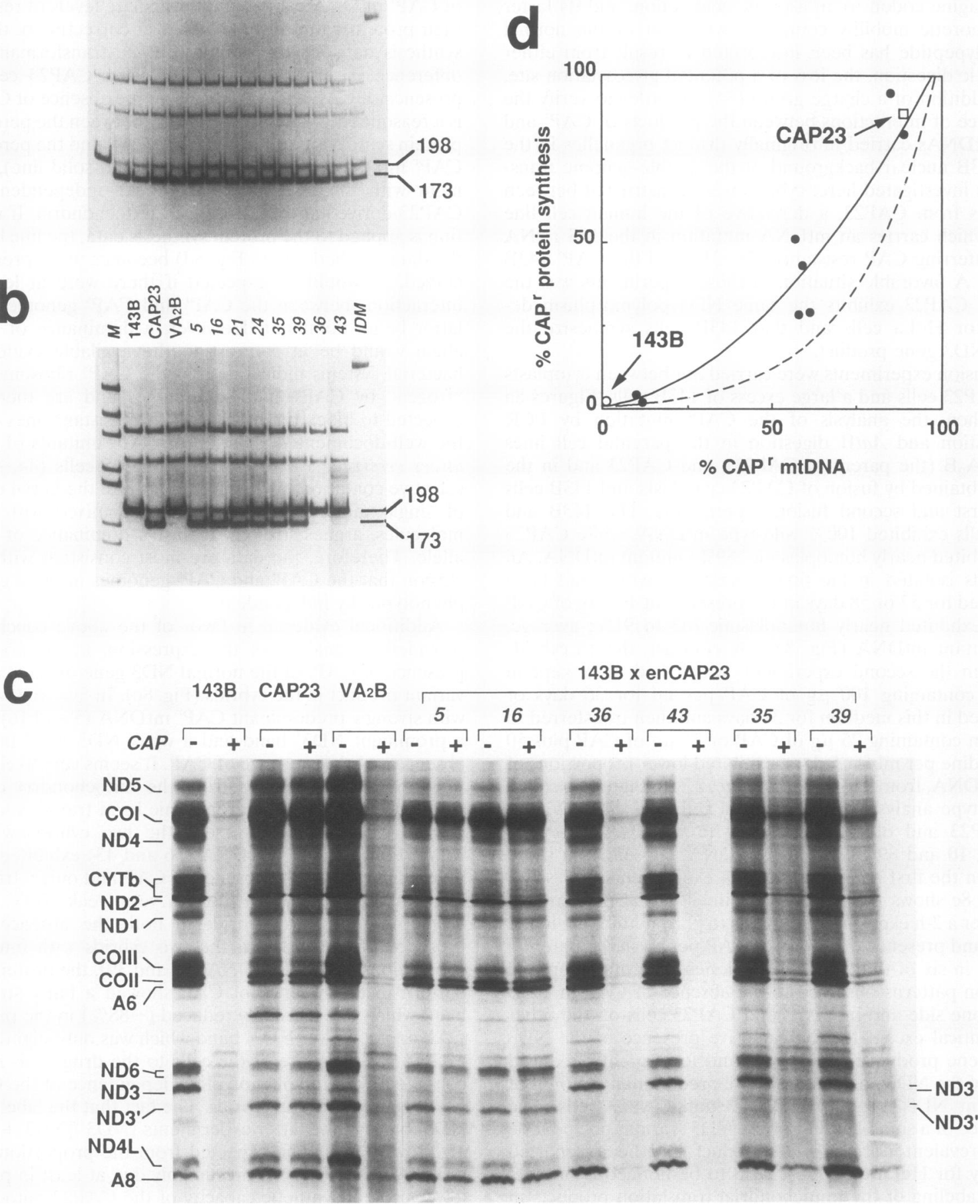

FIG. 8. Genotype and phenotype of cybrids between CAP23 cytoplasts and 143B cells. (a) The CAPr mutation was analyzed in the parental cell lines 143B and CAP23 and in 13 cybrids isolated in the first fusion experiment (time of analysis, 57 days after fusion) by PCR amplification of total cell DNA with a mismatched primer and by running the PCR products on a 5\% polyacrylamide gel, as described in Materials and Methods. Indicated are the size of the uncut PCR product $(198 \mathrm{bp})$ and that of the larger fragment produced by AatII cleavage of the mutation-containing PCR product (173 bp). (b) The CAPr mutation was analyzed in 143B cells, CAP23 cells, $\mathrm{VA}_{2} \mathrm{~B}$ cells, and eight cybrids: of these, two (5 and 16$)$ were isolated in the first fusion experiment (time of analysis, 58 and 59 days after fusion, respectively) and six were isolated in the second fusion experiment, maintained for 31 days in medium containing $100 \mu \mathrm{g}$ of CAP per $\mathrm{ml}$, and then kept for 12 to 17 days in medium containing $25 \mu \mathrm{g}$ of CAP per ml $(35,36$, and 39) or $25 \mu \mathrm{g}$ of CAP plus $50 \mu \mathrm{g}$ of uridine per ml (cybrid 43). (c) Pattern of mitochondrial translation products (25 $\mu \mathrm{g}$ of protein per sample) labeled for $2 \mathrm{~h}$ with $\left.{ }^{35} \mathrm{~S}\right]$ methionine in the absence or presence of $100 \mu \mathrm{g}$ of CAP per ml in 143B cells, CAP23 cells, VA ${ }_{2} \mathrm{~B}$ 
volving the simultaneous introduction into a $\rho^{0} 206$ cell of mitochondria containing mtDNA with a deleterious mutation and the corresponding wild-type mtDNA from the same donor cell, and the other involving the introduction of mitochondria carrying a mutant or wild-type gene into cells already containing the corresponding wild-type or mutant allele. In both situations, transformants exhibiting various ratios of the two types of mtDNA were analyzed.

The first situation was investigated by introducing into $\rho^{0} 206$ cells mitochondria from cells of a patient carrying in heteroplasmic form the mitochondrial tRNA ${ }^{\text {Lys }}$ mutation associated with the MERRF encephalomyopathy. In these experiments, the occurrence of interactions between the products of mutant and wild-type mtDNAs was strongly suggested by the disappearance of the abnormal protein band migrating slightly faster than ND4 $(5,9)$, which is produced as a result of the mutation. Previous observations (9) on $\rho^{0}$ cell transformants carrying the MERRF $A \rightarrow G$ transition in the tRNA ${ }^{\text {Lys }}$ gene had indicated a direct relationship between the lysine residue content of the various mitochondrial translation products and the severity of inhibition of their synthesis, pointing to an alteration of tRNA function as being responsible for the strong depression of mitochondrial protein synthesis caused by the mutation. Although the origin of the abnormal band migrating faster than ND4 has not been identified yet, it is very likely that it represents a premature termination product of the translation of the mRNA for one of the three largest mitochondrial genes, i.e., ND5, COI, and ND4. Recent evidence (14a) has indicated that there is a strong decrease $(60$ to $70 \%)$ in the charging capacity for lysine of the mutated tRNA ${ }^{\text {Lys }}$. In the present work, the almost complete disappearance of the abnormal band in the heteroplasmic transformants containing more than $10 \%$ wild-type mtDNA has clearly shown that there was extensive intermixing of wild-type and mutant gene products in these transformants and that the MERRF mutation behaved as a recessive, a finding which is consistent with a tRNA $^{\text {Lys }}$ dysfunction caused by the mutation. Furthermore, these results have strongly suggested that the protective effect by a small minority of wild-type mtDNA depends, in part at least, on the interaction between the mutant and wild-type gene products.

A strikingly different conclusion from that discussed above concerning mitochondrial genome interactions has emerged from experiments involving the introduction of mitochondria containing a mutant or wild-type gene into cells already carrying the corresponding wild-type or mutant allele. Two such types of experiments were carried out. The first type of experiments took advantage of the availability of two mtDNAs carrying nonallelic disease-causing mutations, each causing a recognizable defective phenotype in the cells carrying it; this allowed a test of the occurrence of complementation between mitochondrial genomes carried by originally distinct organelles, with no significant background being associated with absence of complementation. These experiments involved the introduction into $\rho^{\circ}$ cell transformants nearly homoplasmic for the MELAS mutation of mitochondria carrying about $100 \%$
mtDNA with the MERRF mutation. In these experiments, no evidence of cooperation between the products of the two mtDNAs was observed even 3 months after introduction of the second mutation, as judged from the absence of recovery of respiratory competence and of a normal rate of mitochondrial protein synthesis.

The recessive nature of the MERRF mutation and the observation that as little as $10 \%$ wild-type genes is able to fully complement the biochemical defects caused by the mutation would tend to exclude the possibility that this lack of cooperation between the MERRF and the MELAS genomes reflected an interference by the excess of mutant tRNA ${ }^{\text {Lys }}$ expected in the double-genome transformants analyzed here with the function of the wild-type tRNA ${ }^{\text {Lys }}$. One can likewise exclude the possibility that the majority of the MERRF mutation-carrying genome is "incompatible" with the $\rho^{\mathbf{0}} 206$ nuclear background of the recipient MELAS transformants. In fact, it has been shown previously that the mitochondrial genome of the same haplotype as that investigated here but lacking the MERRF mutation can confer full respiratory competence and a normal level and pattern of mitochondrial protein synthesis on $\rho^{0} 206$ cells (9). In the case of the MELAS mutation, the previously reported full protection from the phenotypic effects of the mutation exerted by $10 \%$ wild-type mtDNA (8) also suggests that the mutation is recessive, arguing against significant interference by the mutated tRNA Leu(UUR) with the wild-type tRNA ${ }^{\text {Leu(UUR) }}$. Even if the MELAS mutation were dominant, it seems extremely unlikely that a minority of MELAS mutation-carrying genomes would have a more drastic effect on mitochondrial protein synthesis and respiration than was previously observed in $\rho^{\mathbf{0}}$ cell transformants carrying nearly $100 \%$ of the same MELAS mutant genomes (8).

The possibility that two unlinked recessive mutations occurring in the same cells may give a dominant phenotype, as has been described for some nuclear systems, also has to be considered. If this is the situation here, it may have produced a result similar to what would be expected from lack of complementation. However, the clear cases of such a phenomenon described previously are those in which the two mutations occur in proteins that interact with each other, like the subunits of an oligomeric complex. In another case, recently reported, concerning the effect of haywire gene mutations in testis-specific tubulin mutants of Drosophila melanogaster (33, 38 ), one mutation alters a protein (haywire) that affects the expression of another gene product ( $\beta$-tubulin) required at high levels, and the other mutation alters the latter gene product. It seems very unlikely that the structural or functional gene product interactions occurring in the two situations mentioned above would apply to the case of two distinct tRNA gene mutations, considering the protective effect of only $10 \%$ wild-type genes against the phenotypic manifestation of either mutation.

On the basis of the evidence discussed above, the most plausible interpretation of the phenotype of the double-genome transformants of $\rho^{0} 206$ cells is that the products of the

cells, and six of the cybrids analyzed in panel b. (d) Relationship between CAP resistance of mitochondrial protein synthesis, estimated from densitometric analysis of the electrophoretic patterns shown in panel c (not shown for cybrids 21 and 24), and proportion of mutant mtDNA in the six cybrids with various levels of CAPr mutation analyzed in panel $\mathrm{c}$ and in two additional cybrid clones (21 and 24) with intermediate levels of CAPr mtDNA (57 and 58\%, respectively) (panel b). Solid circles represent the protein synthesis data for the cybrids after correction for the difference in protein labeling between CAP23 cells in the presence of CAP and $\mathrm{VA}_{2} \mathrm{~B}$ cells in the absence of CAP, and the solid line represents the curve best fitting the data. The CAP23 value has been similarly corrected. The dashed line represents the curve best fitting the uncorrected protein synthesis data. (a and b) IDM, internal digestion marker (see Materials and Methods). (b) Lane M, HaeIII-digested pBluescript KS+ DNA. 
MERRF mutation- and the MELAS mutation-carrying mtDNAs, originally carried in distinct organelles, did not interact with each other to any appreciable extent in the cybrids investigated here. This lack of genome interaction did not reflect the particular behavior of the MELAS and MERRF mutations but rather a more general phenomenon. In fact, similar results were obtained in a second type of experiment involving the introduction of mitochondria from CAP23 cells, carrying a nearly homoplasmic $\mathrm{CAP}^{\mathrm{r}}$ mutation in their mtDNA, into CAP ${ }^{\mathrm{s}} 143 \mathrm{~B}$ cells. In these experiments also, no evidence of genome interaction was observed in the cybrids between the CAPr and CAP mtDNAs, as judged from the reasonably good proportionality between percentage of residual mitochondrial protein synthesis in the presence of CAP and percentage of $\mathrm{CAP}^{\mathrm{r}}$ genomes and from the lack of synthesis, in the presence of the drug, of the 143B mtDNAencoded normal ND3 polypeptide.

The reason for the different conclusion reached by others in similar earlier experiments with cybrids or hybrids between CAP $^{r}$ HT1080 and CAPs HeLa cells (35) is not clear. Although one cannot exclude a role for the different nuclear background in the cybrids analyzed in the present and in the previous work (143B in the present CAPr-CAP ${ }^{\mathrm{s}}$ cybrids and HT1080 in the earlier-investigated $\mathrm{CAP}^{\mathrm{r}}-\mathrm{CAP}^{\mathrm{s}}$ cybrids), it should be remarked that, in the above-cited work, the high sensitivity to CAP (70 to $90 \%$ ) of both the gene products linked to the CAPs mtDNA and of those linked to CAP ${ }^{r}$ mtDNA, including the putative ND3 and ND3' bands, makes those results difficult to interpret. In the present work, additional evidence against any significant cooperation between CAP $^{s}$ and CAPr ${ }^{r}$ mtDNA was provided by the nearly complete replacement of the resident CAP $^{\mathrm{s}}$ mtDNA by the exogenous CAP ${ }^{\mathrm{r}} \mathrm{mtDNA}$ observed in the cybrids 8 weeks after fusion. In fact, if there was such a cooperation, one would expect significant proportions of CAPs mtDNA to persist in the cybrids because of the lack of selective pressure against the CAP ${ }^{\mathrm{s}}$ mtDNA. These results confirm those obtained in earlier experiments, in which single organelles from CAP23 cells were injected into cells from two genetically independent human $\mathrm{CAP}^{\mathrm{s}}$ cell lines. In fact, in these experiments, a rapid complete replacement of the resident CAP $^{\mathrm{s}}$ mtDNA by the CAPr mtDNA was demonstrated (26).

The fundamental conclusion of the experiments discussed in this article is that interactions of mitochondrial genomes originally carried in distinct organelles occur rarely, if at all, in the cell lines analyzed here. Although the present work has not addressed directly the question of whether fusion occurred between organelles carrying different mtDNAs, the most plausible hypothesis is that the lack of interaction between the two genomes reflected their physical segregation in separate organelles, i.e., absence of mitochondrial fusion. There is other evidence in the literature that supports the idea that two types of 'mtDNA originally located in separate organelles tend to remain segregated in mammalian cells, including the gradual elimination of HeLa cell mtDNA in hybrids of HeLa cells and fibroblasts $(21,49)$ and the complete switch, in only one or a few generations, of mtDNA genotypes in Holstein cows $(2,28$, 36). A model assuming that the unit of segregation of mammalian mtDNA is the organelle itself and that the rapidity of segregation of mitochondrial alleles within heteroplasmic oocytes is therefore influenced by whether the individual organelles themselves are homoplasmic or heteroplasmic (23) likewise argues in favor of the genetic independence of the individual mitochondria within a mammalian cell.

The cell mosaicism observed in the distribution of mutant mtDNA in several mtDNA-encoded diseases $(5,9,30,41)$ supports the same concept. The observation of heterogeneity in membrane potential among mitochondria in the same cell is also consistent with autonomy of the organelles (42). In conjugated paramecia also, no complementation has been observed between genetically different types of mitochondria (1). On the other hand, the evidence of mtDNA complementation and recombination clearly indicates that mitochondrial fusion does occur in other organisms, such as $S$. cerevisiae (10), Chlamydomonas spp. (6), and plants $(39,46)$. However, it has also been found in yeast cells that, in $\rho^{+} \times \rho^{+}$crosses, mtDNA mixing is not extensive and appears to be limited to that portion of the zygote which gives rise to medial buds and, furthermore, that the sorting of mtDNA is controlled differently from that of the bulk matrix protein constituents (3). In mammalian cells, the apparent lack of recombination between mtDNA molecules (11) certainly reduces the need for mitochondrial fusion. However, in mammalian systems, the evidence for the existence of an interconnecting mitochondrial network in some cell types in vivo also suggests the possibility that mitochondrial fusion may occur in certain situations under physiological or developmental control.

The observation of restoration of normal mitochondrial protein synthesis in $\rho^{0}$ cell transformants derived from heteroplasmic cells from an MERRF patient and containing more than $10 \%$ wild-type mtDNA and the previously reported findings of fusion proteins (20) and of competition for tRNAs (41) in cybrids and skeletal muscle segments carrying large mtDNA deletions have to be interpreted in the light of the evidence obtained in the present work on the lack of interactions between the products of two mtDNAs carried by originally distinct organelles. In fact, it seems likely that, in all the above-mentioned cases, in which there was obviously interaction of the mutant and wild-type genomes, these coexisted in the same organelles from the time of the mutation. Since each mitochondrion in most mammalian cells contains several mtDNA molecules, every mutant mtDNA molecule will in the beginning coexist in the same organelle with wild-type molecules. It is very reasonable to think that cells in which this intramitochondrial heteroplasmy is maintained will have a selective advantage because of the possibility of complementation that this situation allows. Therefore, the different results obtained in the two situations analyzed in the present work, namely, the occurrence of interactions of mutant and wild-type mitochondrial DNAs originally coexisting in the same cell and the failure of interaction when the two DNAs are introduced into a cell within distinct organelles, may well reflect the different complementation behavior of the two DNAs in the case of intramitochondrial versus intermitochondrial heteroplasmy. If this interpretation is correct, it would imply a fundamental role for mtDNA sorting among different organelles in determining the oxidative phosphorylation phenotype in mammalian cells.

It seems indeed a very plausible idea that mitochondrial organization, which is under nuclear control and varies among different cell types, may be an important parameter affecting mitochondrial gene expression in these cells. The present observations have significant implications for the possible role of genetic independence of individual mitochondria in the transmission of mtDNA-encoded diseases and for potential therapeutic approaches involving mtDNA- or mitochondrionmediated gene transfer.

\section{ACKNOWLEDGMENTS}

These investigations were supported by National Institutes of Health grant GM-11726 to G.A., Muscular Dystrophy Association 
grant 37826 to G.A. and Anne Chomyn, and a Gosney Fellowship and a Human Frontier Science Program Fellowship to M.Y.

We are very grateful to A. Chomyn for providing clone pT72. The technical assistance of A. Drew, B. Keeley, and L. Tefo is gratefully acknowledged.

\section{REFERENCES}

1. Adoutte, A., A. Sainsard, M. Rossignol, and J. Beisson. 1973. Aspects génétiques de la biogenèse des mitochondries chez la paramecie. Biochimie 55:793-799.

2. Ashley, M. V., P. J. Laipis, and W. W. Hauswirth. 1989. Rapid segregation of heteroplasmic bovine mitochondria. Nucleic Acids Res. 17:7325-7331.

3. Azpiroz, R., and R. A. Butow. 1993. Patterns of mitochondrial sorting in yeast zygotes. Mol. Biol. Cell 4:21-36.

4. Birky, C. W. J. 1973. On the origin of mitochondrial mutants: evidence for intracellular selection of mitochondria in the origin of antibiotic-resistant cells in yeast. Genetics 74:421-432.

5. Boulet, L., G. Karpati, and E. A. Shoubridge. 1992. Distribution and threshold expression of the tRNA ${ }^{\text {Lys }}$ mutation in skeletal muscle of patients with myoclonic epilepsy and ragged-red fibers (MERRF). Am. J. Hum. Genet. 51:1187-1200.

6. Boynton, J. E., E. H. Harris, B. D. Burkhart, P. M. Lamerson, and N. W. Gillham. 1987. Transmission of mitochondrial and chloroplast genomes in crosses of Chlamydomonas. Proc. Natl. Acad. Sci. USA 84:2391-2395.

7. Bunn, C. L., C. H. Mitchell, H. B. Lukins, and A. W. Linnane. 1970. Biogenesis of mitochondria. XVIII. A new class of cytoplasmically determined antibiotic resistant mutants in Saccharomyces cerevisiae. Proc. Natl. Acad. Sci. USA 67:1233-1240.

8. Chomyn, A., A. Martinuzzi, M. Yoneda, A. Daga, O. Hurko, D. Johns, S. T. Lai, I. Nonaka, C. Angelini, and G. Attardi. 1992. MELAS mutation in mtDNA binding site for transcription termination factor causes defects in protein synthesis and in respiration but no change in levels of upstream and downstream mature transcripts. Proc. Natl. Acad. Sci. USA 89:4221-4225.

9. Chomyn, A., G. Meola, N. Bresolin, S. T. Lai, G. Scarlato, and G. Attardi. 1991. In vitro genetic transfer of protein synthesis and respiration defects to mitochondrial DNA-less cells with myopathy-patient mitochondria. Mol. Cell. Biol. 11:2236-2244.

10. Clark-Walker, G. D., and G. L. G. Miklos. 1975. Complementation in cytoplasmic petite mutants in yeast to form respiratory competent cells. Proc. Natl. Acad. Sci. USA 72:372-375.

11. Clayton, D. A. 1982. Replication of animal mitochondrial DNA. Cell 28:693-705.

12. Corral-Debrinski, M., T. Horton, M. T. Lott, J. M. Shoffner, M. Flint Beal, and D. C. Wallace. 1992. Mitochondrial DNA deletions in human brain: regional variability and increase with advanced age. Nature Genet. 2:324-329.

13. Cortopassi, G. A., and N. Arnheim. 1990. Detection of a specific mitochondrial DNA deletion in tissues of older humans. Nucleic Acids Res. 18:6927-6933.

14. Cortopassi, G. A., D. Shibata, N.-W. Soong, and N. Arnheim. 1992. A pattern of accumulation of a somatic deletion of mitochondrial DNA in aging human tissues. Proc. Natl. Acad. Sci. USA 89:73707374.

14a.Enriquez, A., and G. Attardi. Unpublished data.

15. Feinberg, A. P., and B. Vogelstein. 1983. A technique for radiolabelling DNA restriction endonuclease fragments to high specific activity. Anal. Biochem. 132:6-13.

16. Gonzalez, I. L., J. L. Gorski, T. J. Campen, D. J. Dorney, J. M. Erickson, J. E. Sylvester, and R. D. Schmickel. 1985. Variation among human $28 \mathrm{~S}$ ribosomal RNA genes. Proc. Natl. Acad. Sci. USA 82:7666-7670.

17. Goto, Y.-I., I. Nonaka, and S. Horai. 1990. A mutation in the tRNA ${ }^{\text {Leu(UUR) }}$ gene associated with the MELAS subgroup of mitochondrial encephalomyopathies. Nature (London) 348:651653.

18. Gurgo, C., D. Apirion, and D. Schlessinger. 1969. Polyribosome metabolism in Escherichia coli treated with chloramphenicol, neomycin, spectinomycin or tetracycline. J. Mol. Biol. 45:205-220.

19. Hayakawa, M., K. Hattori, S. Sugiyama, and T. Ozawa. 1992. Age associated oxygen damage and mutations in mitochondrial DNA in human hearts. Biochem. Biophys. Res. Commun. 189:979-985.

20. Hayashi, J.-I., S. Ohta, A. Kikuchi, M. Takemitsu, Y.-I. Goto, and I. Nonaka. 1991. Introduction of disease-related mitochondrial DNA deletions into HeLa cells lacking mitochondrial DNA results in mitochondrial dysfunction. Proc. Natl. Acad. Sci. USA 88: 10614-10618.

21. Hayashi, J.-I., H. Werbin, and J. W. Shay. 1986. The effects of normal human fibroblast mitochondrial DNA on the segregation of $\mathrm{HeLa}$ TG mitochondrial DNA and on the tumorogenicity of HeLa TG cells. Cancer Res. 46:4001-4006.

22. Horai, S. 1990. Molecular phylogeny and evolution of human mitochondrial DNA, p. 135-152. In M. Kimura and N. Yakahata (ed.), New aspects of genetics in molecular evolution. Japan Scientific Society Press, Tokyo.

23. Howell, N., S. Halvorson, I. Kubacka, D. A. Mccullough, and L. A. Bindoff. 1992. Mitochondrial gene segregation in mammals-Is the bottleneck always narrow? Hum. Genet. 90:117-120.

24. Kawasaki, E. S. 1990. Sample preparation from blood, cells, and other fluids, p. 146-152. In M. A. Innis, D. H. Gelfold, J. J. Siniuski, and T. J. White (ed.), PCR protocols: a guide to methods and applications. Academic Press, San Diego.

25. King, M. P., and G. Attardi. 1989. Human cells lacking mtDNA: repopulation with exogenous mitochondria by complementation. Science 246:500-503.

26. King, M. P., and G. Attardi. 1988. Injection of mitochondria into human cells leads to a rapid replacement of the endogenous mitochondrial DNA. Cell 52:811-819.

26a.King, M. P., and G. Attardi. Unpublished data.

27. Kobayashi, Y., M. Y. Momoi, K. Tominaga, T. Momoi, K. Nihei, M. Yanagisawa, Y. Kagawa, and S. Ohta. 1990. A point mutation in the mitochondrial tRNA ${ }^{\text {Leu(UUR) }}$ gene in MELAS (mitochondrial myopathy, encephalopathy, lactic acidosis and strokelike episodes). Biochem. Biophys. Res. Commun. 173:816-822.

28. Koehler, C. M., G. L. Lindberg, D. R. Brown, D. C. Beitz, A. E. Freeman, J. E. Mayfield, and A. M. Myers. 1991. Replacement of bovine mitochondrial DNA by a sequence variant within one generation. Genetics 129:247-255.

29. Meola, G., E. Scarpini, M. Velicogna, A. Mottura, P. L. Baron, S. Beretta, and G. Scarlato. 1986. Analysis of fibronectin expression during human muscle differentiation. Basic Appl. Histochem. 30:153-163.

30. Mita, S., B. Schmidt, E. A. Schon, S. DiMauro, and E. Bonilla. 1989. Detection of "deleted" mitochondrial genome in cytochrome-c oxidase deficient muscle fibers of a patient with KearnsSayre syndrome. Proc. Natl. Acad. Sci. USA 86:9509-9513.

31. Mitchell, C. H., and G. Attardi. 1978. Cytoplasmic transfer of chloramphenicol resistance in a human cell line. Somat. Cell Genet. 4:737-744.

32. Mitchell, C. H., J. M. England, and G. Attardi. 1975. Isolation of chloramphenicol resistant variants from a human cell line. Somat. Cell Genet. 1:215-234.

33. Mounkes, L. C., R. S. Jones, B.-C. Liang, W. Gelbart, and M. T. Fuller. 1992. A Drosophila model for xeroderma pigmentosum and Cockayne's syndrome: haywire encodes the fly homolog of ERCC3, a human excision repair gene. Cell 71:925-937.

34. Oliver, N. A., B. D. Greenberg, and D. C. Wallace. 1983. Assignment of a polymorphic polypeptide to the human mitochondrial DNA unidentified reading frame 3 gene by a new peptide mapping strategy. J. Biol. Chem. 258:5834-5839.

35. Oliver, N., and D. C. Wallace. 1982. Assignment of two mitochondrially synthesized polypeptides to human mitochondrial DNA and their use in the study of intracellular mitochondrial interaction. Mol. Cell. Biol. 2:30-41.

36. Olivo, P. D., M. J. Van de Walle, P. J. Laipis, and W. W. Hauswirth. 1983. Nucleotide sequence evidence for rapid genotype shift in the bovine mitochondrial DNA D-loop. Nature (London) 306:400-402.

37. Ozawa, T., M. Yoneda, M. Tanaka, K. Ohno, W. Sato, H. Suzuki, M. Nishikimi, M. Yamamoto, I. Nonaka, and S. Horai. 1988 Maternal inheritance of deleted mitochondrial DNA in a family with mitochondrial myopathy. Biochem. Biophys. Res. Commun. 154:1240-1247.

38. Regan, C. L., and M. T. Fuller. 1988. Interacting genes that affect 
microtubule function: the $n c 2$ allele of the haywire locus fails to complement mutations in the testis-specific $\beta$-tubulin gene of Drosophila. Genes Dev. 2:82-92.

39. Rothenberg, M., M. L. Boeshore, M. R. Hanson, and S. Izhar. 1985. Intergenomic recombination of mitochondrial genomes in a somatic hybrid plant. Curr. Genet. 9:615-618.

40. Shoffiner, J. M., M. T. Lott, A. M. S. Lezza, P. Seibel, S. W. Ballinger, and D. C. Wallace. 1990. Myoclonic epilepsy and ragged-red fiber disease (MERRF) is associated with a mitochondrial DNA tRNA ${ }^{\text {Lys }}$ mutation. Cell 61:931-937.

41. Shoubridge, E. A., G. Karpati, and K. E. M. Hastings. 1990. Deletion mutants are functionally dominant over wild-type mitochondrial genomes in skeletal muscle fiber segments in mitochondrial disease. Cell 62:43-49.

42. Smiley, S. T., M. Reers, C. Mottola-Hartshorn, M. Lin, A. Chen, T. W. Smith, G. D. Steele, Jr., and L. B. Chen. 1991. Intracellular heterogeneity in mitochondrial membrane potentials revealed by a J-aggregate-forming lipophilic cation JC-1. Proc. Natl. Acad. Sci. USA 88:3671-3675.

43. Soong, N. W., D. R. Hilton, G. Cortopassi, and N. Arnheim. 1992. Mosaicism for a specific somatic mitochondrial DNA mutation in adult human brain. Nature Genet. 2:318-323.

44. Spolsky, C. M., and J. M. Eisenstadt. 1972. Chloramphenicolresistant mutants of human HeLa cells. FEBS Lett. 25:319-324.

45. Tanaka, M., H. Ino, K. Ohno, T. Ohbayashi, S.-I. Ikebe, T. Sano, T. Ichiki, M. Kobayashi, Y. Wada, and T. Ozawa. 1991. Mitochondrial DNA mutations in mitochondrial myopathy, encephalopathy, lactic acidosis, and stroke-like episodes (MELAS). Biochem.
Biophys. Res. Commun. 174:861-868.

46. Vedel, F., P. Chetrit, C. Mathieu, G. Pelletier, and C. Primard. 1986. Several different mitochondrial-DNA regions are involved in intergenomic recombination in Brassica-Napus hybrid plants. Curr. Genet. 11:17-24.

47. Wallace, D. C. 1992. Diseases of the mitochondrial DNA. Annu. Rev. Biochem. 61:1175-1212.

48. Wallace, D. C. 1981. Assignment of the chloramphenicol resistance gene to mitochondrial deoxyribonucleic acid and analysis of its expression in cultured human cells. Mol. Cell. Biol. 1:697-710.

49. White, F. A., and C. L. Bunn. 1984. Segregation of mitochondrial DNA in human somatic cell hybrids. Mol. Gen. Genet. 197:453460.

50. Wiseman, A., and G. Attardi. 1982. Cytoplasmically determined human cell mutants defective in mitochondrial ribosome assembly. Mol. Gen. Genet. 186:364-371.

51. Yoneda, M., A. Chomyn, A. Martinuzzi, O. Hurko, and G. Attardi. 1992. Marked replicative advantage of human mtDNA carrying a point mutation that causes the MELAS encephalomyopathy. Proc. Natl. Acad. Sci. USA 89:11164-11168.

52. Yoneda, M., Y. Tanno, I. Nonaka, T. Miyatake, and S. Tsuji. 1991. Simple detection of tRNA ${ }^{\text {Lys }}$ mutation in MERRF (myoclonus epilepsy associated with ragged-red fibers) by polymerase chain reaction with a mismatched primer. Neurology 41:1838-1840.

53. Yoneda, M., Y. Tanno, S. Horai, T. Ozawa, T. Miyatake, and S. Tsuji. 1990. A common mitochondrial DNA mutation in the t-RNA ${ }^{\text {Lys }}$ of patients with myoclonus epilepsy associated with ragged-red fibers. Biochem. Int. 21:789-796. 